Journal of Educational

and Psychological Sciences

Volume (5), Issue (30): 30 Aug 2021

P: 1 - 26

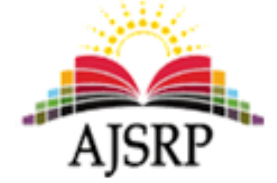

ISSN: 2522- 3399

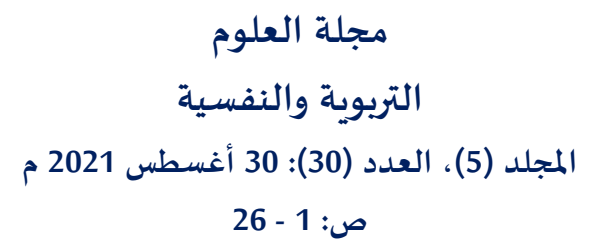

مجلة العلوم

التربوية والنفسية

ص: 1 - 26

\title{
The reality of applying electronic supervision in public schools during the Corona pandemic period from the point of view of educational supervisors in the Northern Region of Jordan
}

\author{
Wafaa Ahmed Bakheet \\ Directorate of Northern Jordan Education || Ministry of Education || Jordan
}

\begin{abstract}
The study aimed to identify the reality of the application of electronic supervision in public schools during the period of the Corona pandemic from the point of view of educational supervisors in the Northern Region in Jordan, depending on the changing gender and years of experience supervisory and specialization. The research adopted the descriptive analytical approach. The researcher took from (the questionnaire) a main tool to take the opinions of the members of the sample of the study consisting of 50 supervisors.

The results of the research showed the reality of the application of electronic supervision in public schools during the period of the Corona pandemic from the point of view of educational supervisors in the Northern Region in Jordan at the level of the whole tool obtained a total level (3.98 out of 5) with a rating (high). At the field level: the area (barriers to the use of electronic supervision) received the highest average (4.21) rating (very high). This is followed by the field (the importance of educational supervision) where the average (3.98), the field (the application of electronic supervision in supervisory work) where the level of response was (3.91), and finally the field (the concept of electronic supervision) where the level of response was (3.80), all are rated (high).

It also showed that there were no statistically significant differences at the level of $(\alpha \leq 0.05)$ the reality of the application of electronic supervision in public schools during the corona pandemic period from the point of view of educational supervisors in the Northern Region in Jordan due to the change of gender and years of experience supervisory and specialization in all dimensions and the overall degree where the level of significance of the values $(T)$ was greater than (0.05).
\end{abstract}

The researcher recommended the adoption of integrated education in Jordanian schools, even after the Corona pandemic, to meet exceptional circumstances. The educational supervisor should develop his supervisory practices to conform to the circumstances of the Corona pandemic and to the requirements of e- learning. Finally, the teacher is supported by educational media that he or she can rely on when designing his e- lessons.

Keywords: Electronic Supervision, Corona Pandemic, Educational Supervisor.

$$
\begin{aligned}
& \text { واقع تطبيق الإشراف الإلكتروني في المدارس الحكومية خلال فترة جائحة كورونا } \\
& \text { من وجهة نظر المشرفين التربويين في إقليم الشمال بالأردن الشين } \\
& \text { وفاء أحمد بخيت } \\
& \text { مديرية تربية الأغوار الشمالية || وزارة التربية والتعليم || الأردن }
\end{aligned}
$$




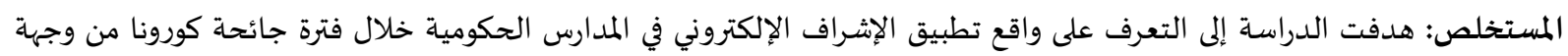

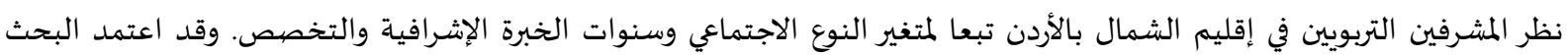

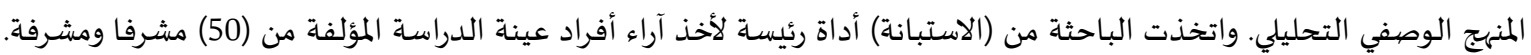

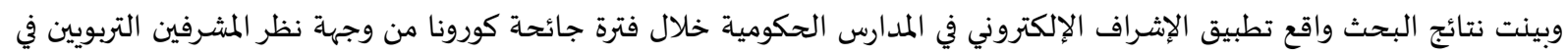

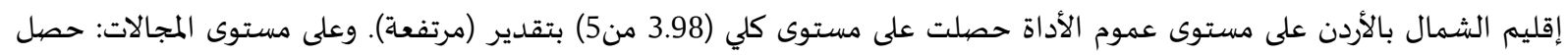

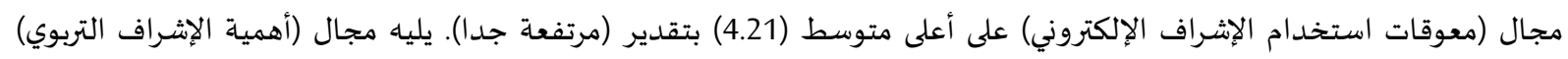

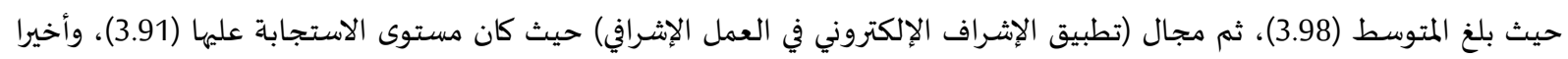

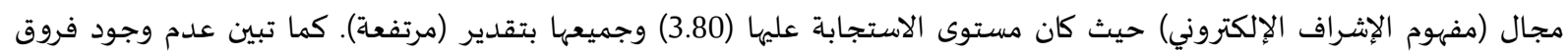

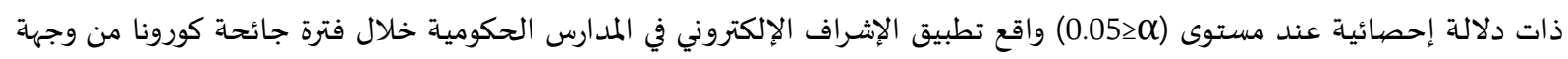

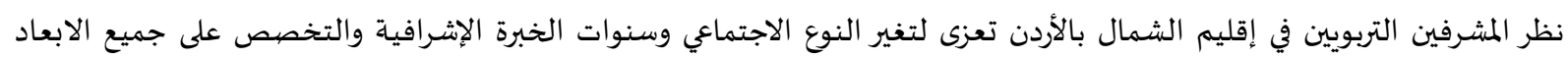

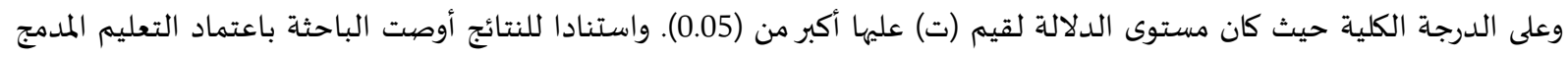

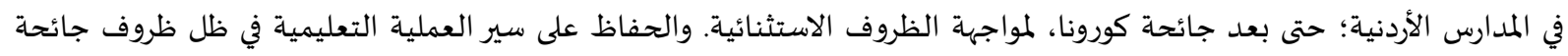

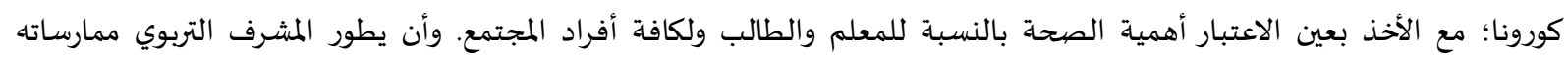

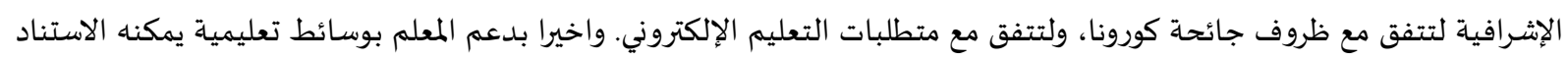
إلهيها عند تصميم دروسه الإلكترونية.

الكلمات المفتاحية: الإشراف الإلكتروني، جائحة كورونا، المشرف التربوي.

المقدمة.

في عصر تسارعت فيه حركة العلوم والمعارف، وغدت تقنية المعلومات والتقدم الإلكتروني هما المسيطران

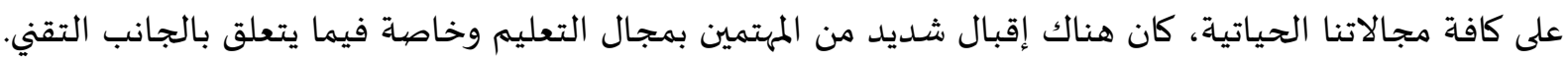

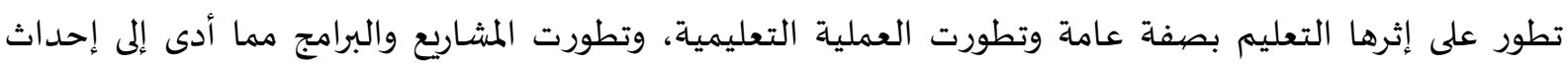
قفزة مذهلة غيرت مجرى الحياة وذلك من خلال أداء رسالة كبيرة تقع على عاتق كافة القائمين على العملية التعليمية (كسارة وعطار، 2013؛؛ (Van Hornet al).

ومنهم المشرف التربوي الذي قام بدوره بنشر سياستها وثقافتها في الميدان التربوي ليتم التأثير والتأثر في

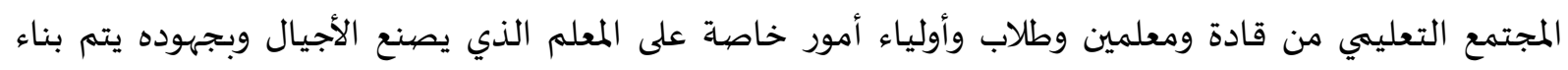

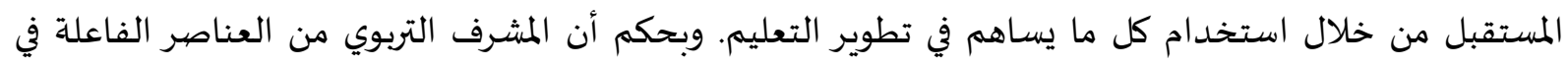
العملية التعليمية لاتخاذه موقعا مهما وأساس في تحقيق العديد من التطلعات والأهداف، فهو يعتبر مرشدا ومات وموجها

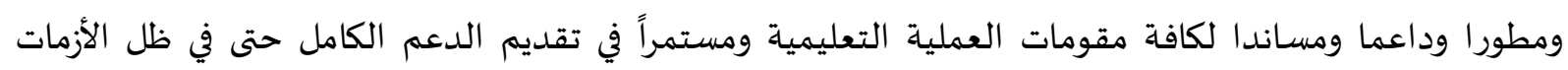
الطارئة، خاصة أن دوره لا يقتصر على الميدان التربوي التقليدي بل يتجاوزه إلى العمل على الاتصال الإلكتروني.

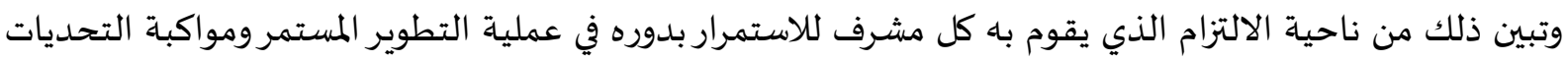

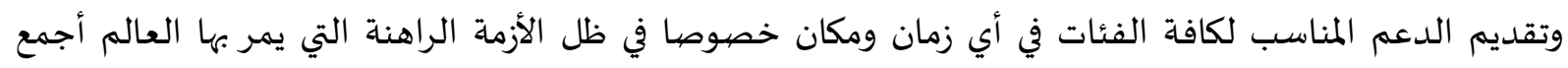

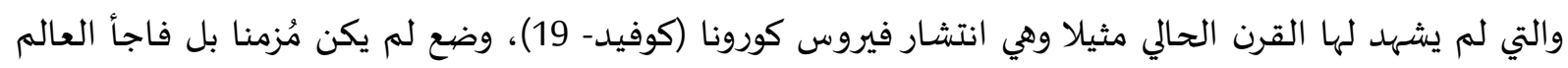

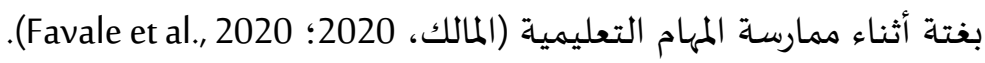

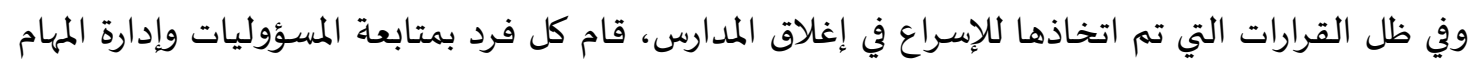

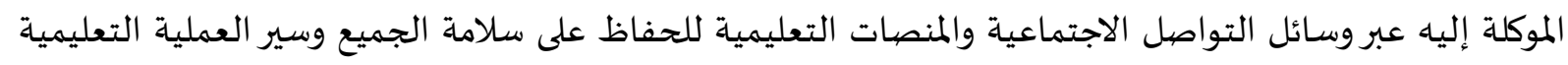

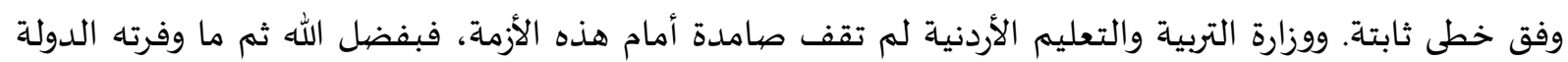

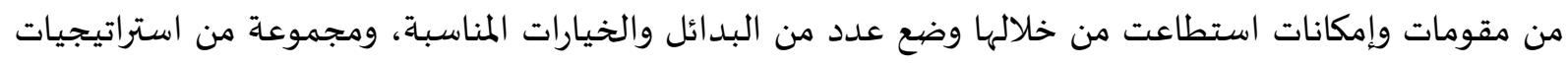


التعليم عن بُعد لمواجهة هذه الأزمة، الأمر الذي أتاح الفرصة لمعظم الطلبة بأخذ حقهم من التعليم بصورة متكافئة

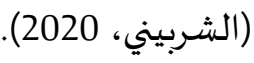

ويقف الآن دور المشرف التربوي بدوره المتابع، المدرب، الموجه، المقوم، والمقدم للتغذية الراجعة على لمانى

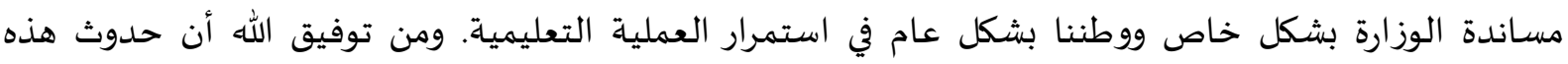

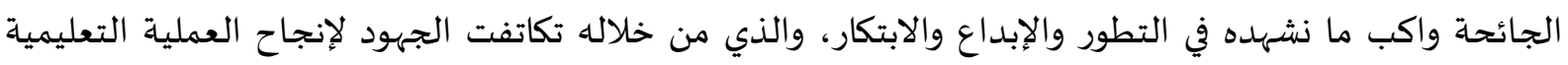

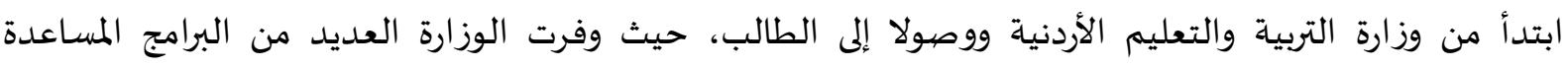

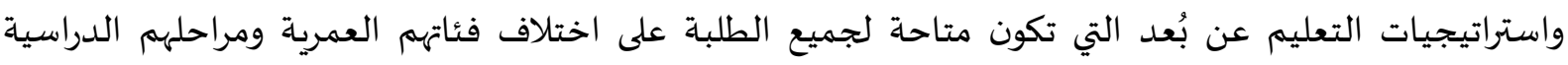
لتستمر العملية التعليمية عن بُعد (المالك، 2020).

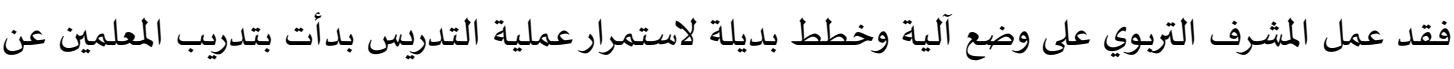

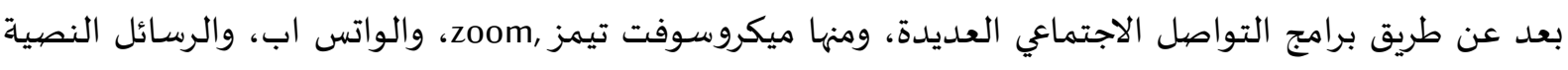

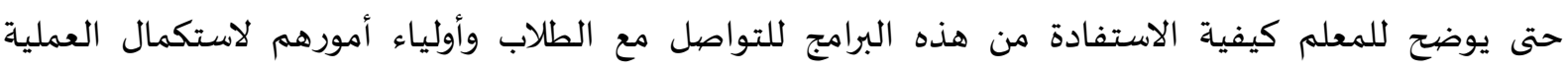

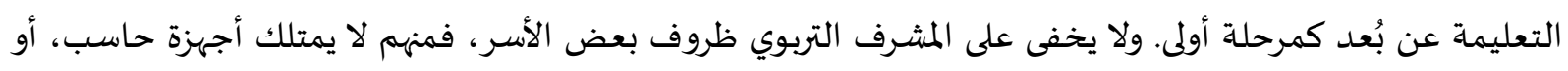

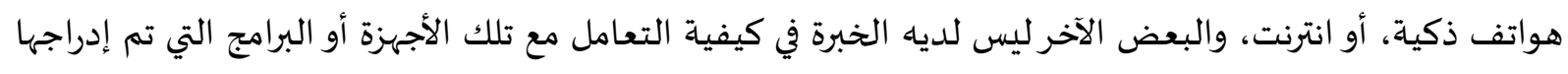

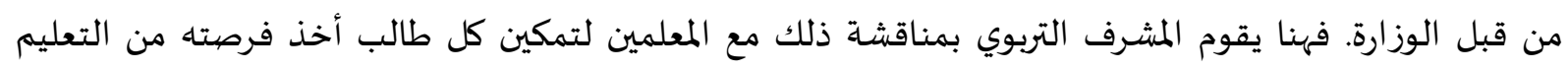

(MOE, 2019)

أما المرحلة الثانية تم مناقشة آلية استخدام البرامج التي تم إدراجها من قبل وزارة التربية والتعليم وكيفية تفعيلها، كمنصة درسك التعليمية والطريقة المثلى لتفعيلها والاستفادة منها. المرحلة الثالثة يقوم المعلم بدوره بالتواصل مع الطلاب وإعطائهم التعليمات لتفعيل هذه البرامج ومتابعتهم من خلالله، فيقوم المعلم بإدراج الواجبات ولاتهات والاختبارات المتنوعة وبالإضافة على ذلك شرح لبعض الدروس الدوس من خلال تلك المنصيات (MOE) 2019)..

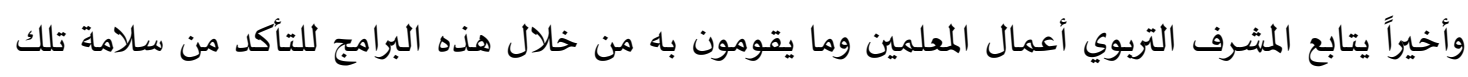

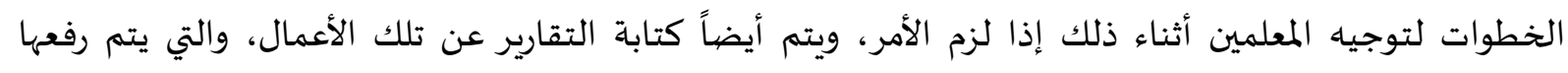

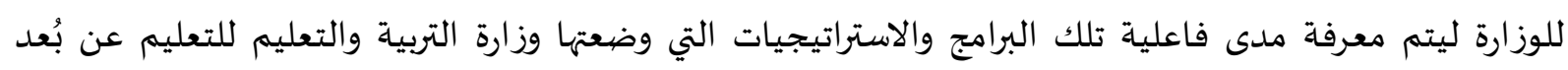

(MOE, 2019)

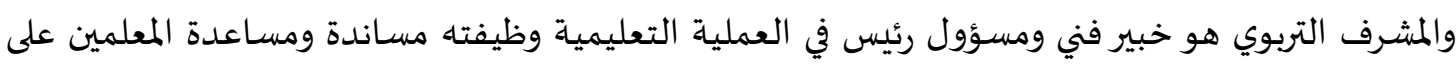

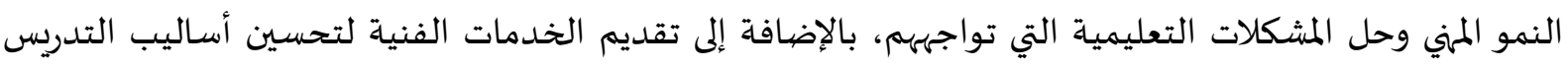

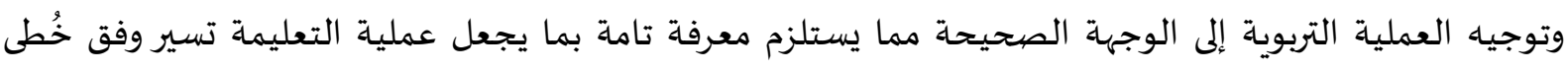
ثابتة (السليم، 2008). وقد أشار السرحان (2011) إلى أن الإشراف التربوي عملية فعالة قادرة على تحسين نوعية التعلم والتعليم، في غرفة الصف، والإشراف في أرقى مستوياته ديناميكي وديمقراطي يتمتع بقيادة حيوية مستنيرة وعلمياة، وهدفها

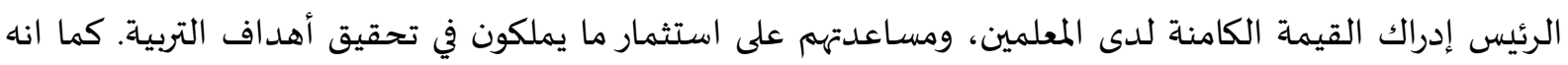

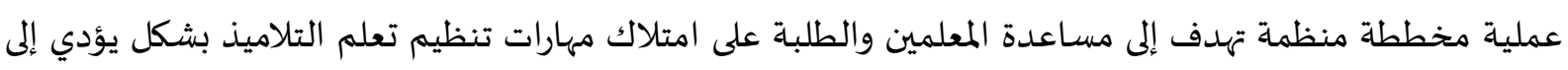
تقييم الأهداف التعليمية والتربوية (خلف الله، 2014). وهو نظام يهتم بكافة عناصر العمل التهبة التربوي، ويسهم في تحقيق الأهداف التعليمية، ويتضمن جهود وممارسات متلاحقة ومتسقة ببعضها لتقييم مجريات العملية التعليمية،

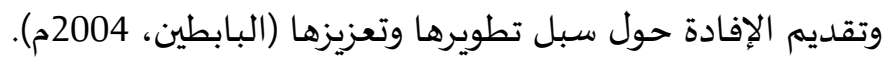


أما نمط الإشراف الإلكتروني فقد عرفه الشمراني (2008) انه عبارة عن نمط إشرافي يقدم أعمال ومهام

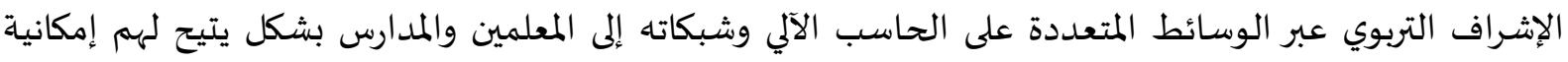

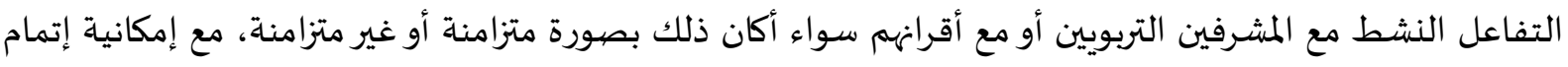

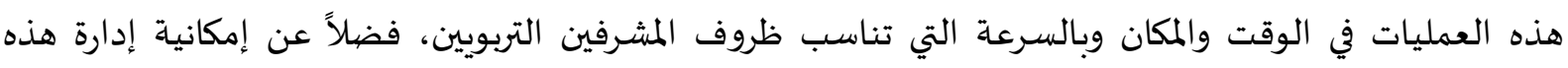

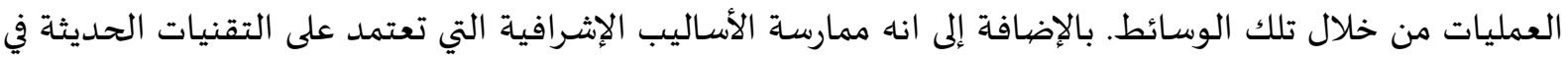

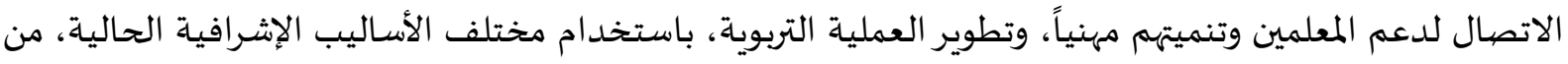

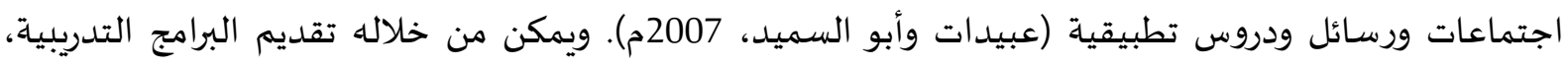

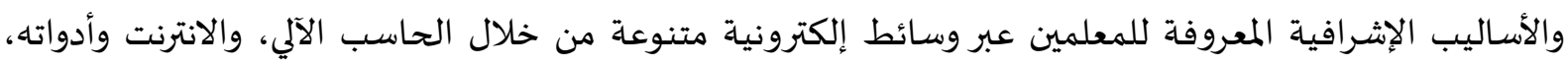

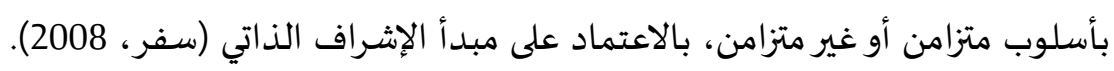

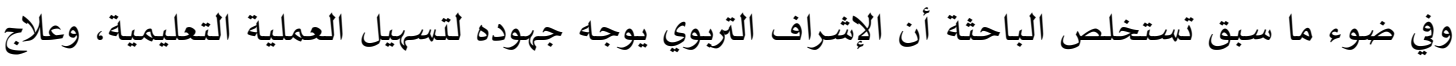

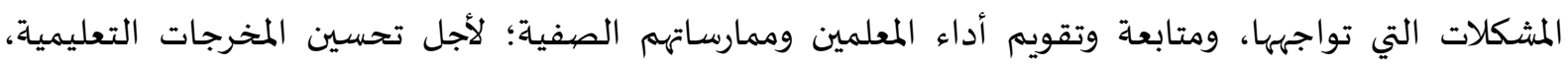

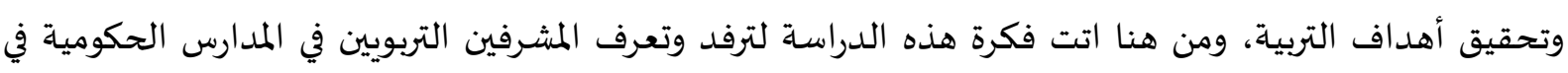

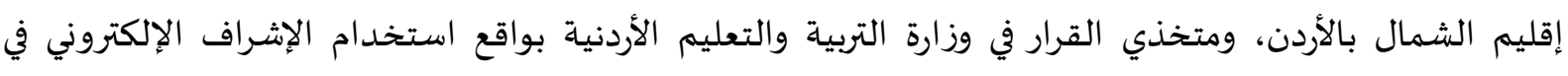
المدارس الحكومية في ظل تداعيات جائحة كورونا، ودوره في تحفيز المعلمين على تطبيق التعليم الإلكتروني والمتابعة الإنة الإلكترونية لهم.

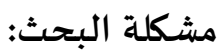

إن استخدام التقنيات والوسائط الإلكترونية الحديثة في عمليتي التعليم والتعلم لم تعد ترفاً بل ضرورة فرضتها التطورات التكنولوجية الهائلة، وهو أسلوب أثر على دور المعلم والمتعلم، لأن مهاراتهم المطلوبة التحلية في التعليم

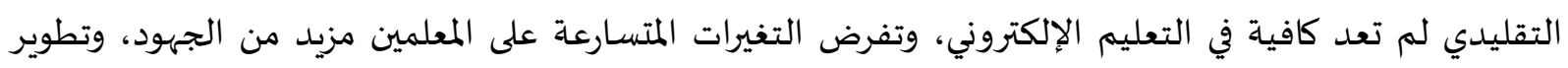
الذات.

والتعليم الإلكتروني كمفهوم ظهر حديثاً؛ لكنه أثر على كافة عناصر العملية التعليمية، فظهرت مفاهيم:

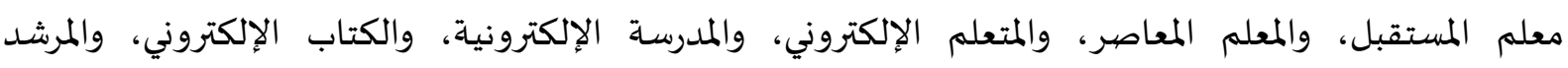
الافتراضي، والجامعة الافتراضية، والإشراف التربوي الإلكتروني، وجميعها تسير في فلك التعليم الإلكتروني في عملية الإنية الإنية التعليم والتعلم.

كذلك يعد دور الإشراف التربوي محورياً في عمليات التربية والتعليم، فمنظومة الإشراف التربوي تعد حلقة الوصل بين أطراف العملية التعليمية، ويقع على عاتقه مساعدة المعلمين على حل المشكلات التربوية؛ وبظهور جائحة

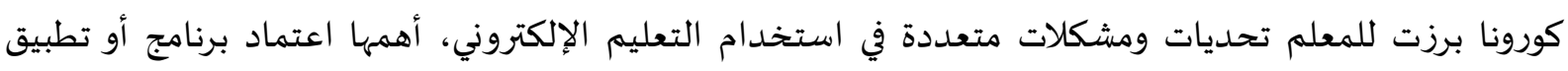

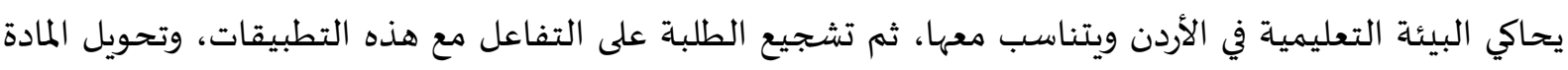

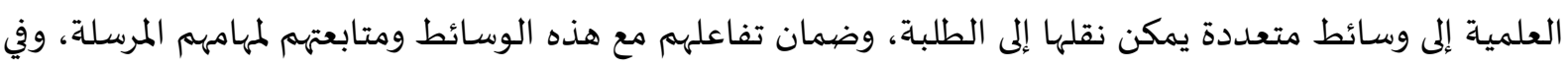

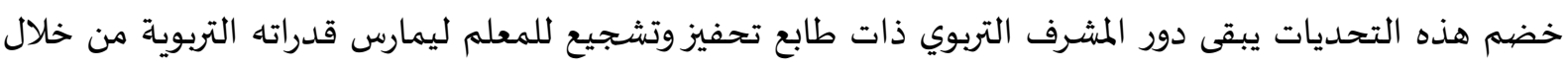
التعليم الإلكتروني.

لقد زاد الاهتمام من قبل وزارة التربية والتعليم الأردنية بتطوير الإشراف التربوي في السنوات الأخيرة نتيجة

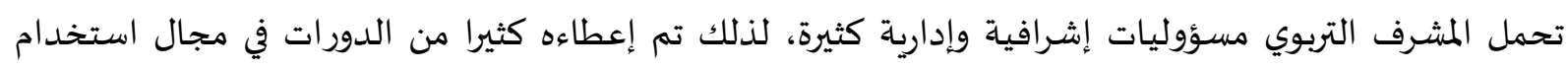

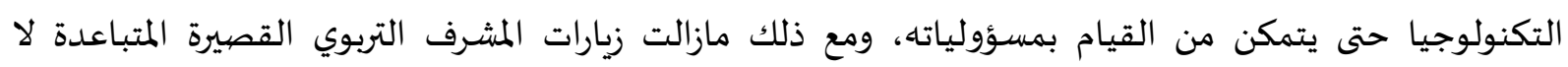


تساعد المعلم على النمو المهني، إنما هي على أفضل الأحوال قد تكشف عن جوانب القصور لدياه نتيجة قيام المشرف

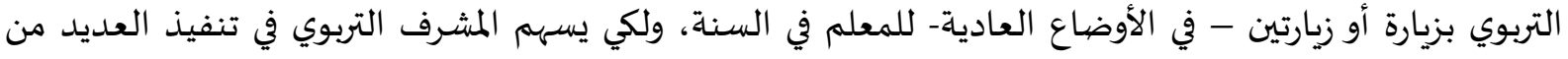

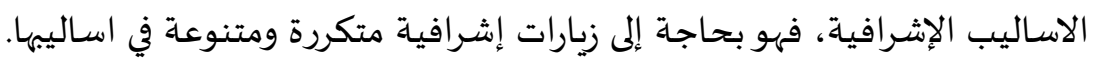

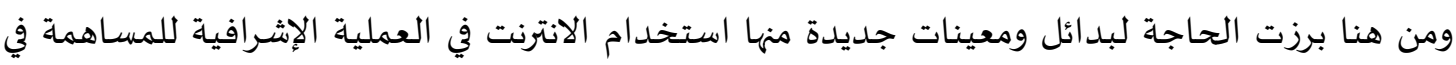

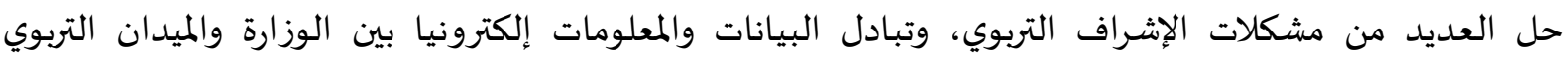

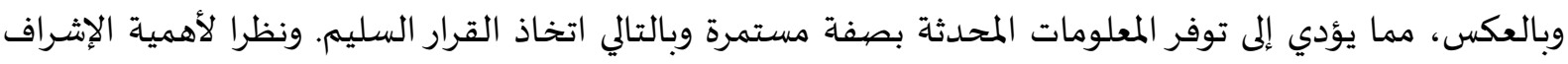

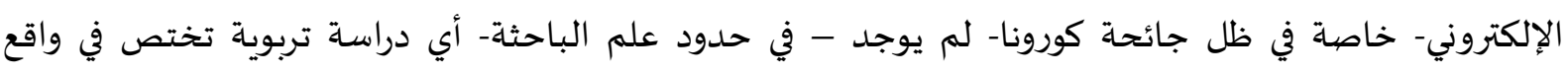
استخدام الإشراف الإلكتروني في المدارس الحكومية في إقليم الشمال بالألأردن.

أسئلة الدراسـة:

تتحدد مشكلة الدراسة في الأسئلة التالية: 1. ما واقع تطبيق الإشراف الإلكتروني في المدارس الحكومية من وجهة نظر المشرفين التربويين في إقليم الشمال

بالأردن؟ 2. هل يختلف واقع تطبيق الإشراف الإلكتروني في المدارس الحكومية من وجهة نظر المشرفين التربويين في إقليم

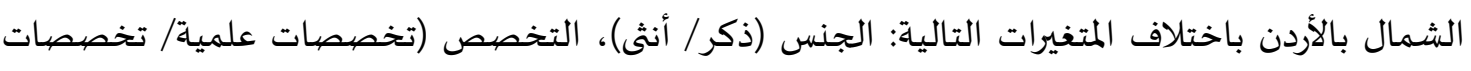

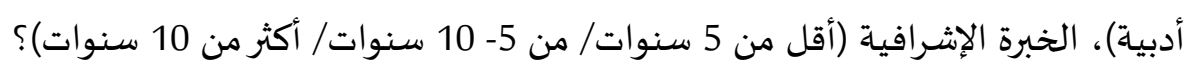

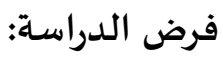

تسعى الدارسة إلى فحص الفرضيات الصفرية الآتية:

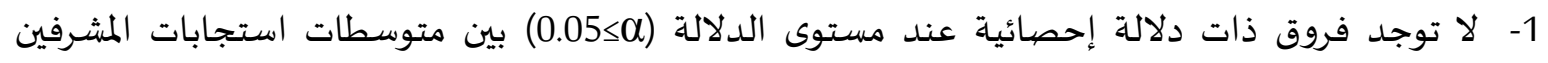

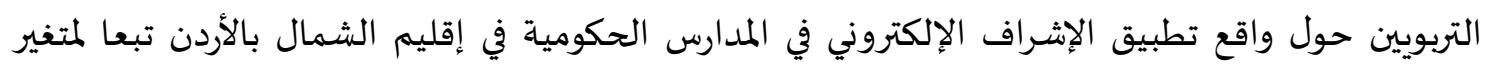
الجنس (ذكر، أنثى). 2- لا توجد فروق ذات دلالة إحصائية عند مستوى الدلالة(م>0.05) بين متوسطات استجابات المشرفين

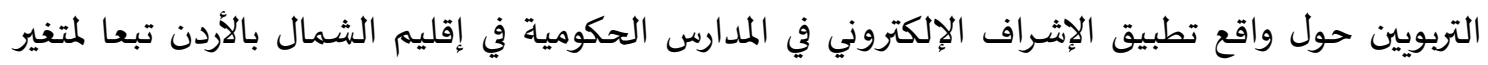

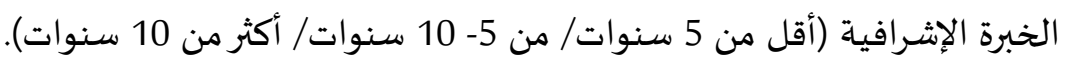

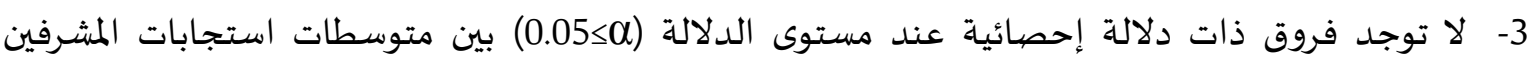

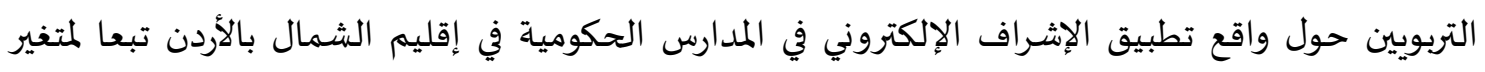

التخصص (تخصصات علمية/ تخصصات أدبية).

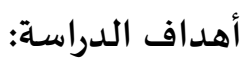

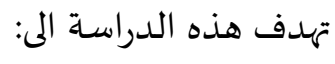

1- الوقوف على واقع تطبيق الإشراف الإلكتروني في المدارس الحكومية في إقليم الشمال من وجهة نظر المشرفين

التربويين.

2- التعرف على الفروق في واقع استخدام الإشراف الإلكتروني تبعا لمتغيرات الدراسة.

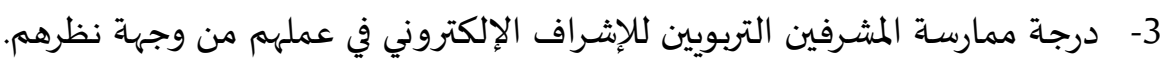


4- تحديد متطلبات تطبيق الإشراف الإلكتروني في الميدان التربوي لتحقيق أهداف الإشراف التربوي وتحديد الصعوبات التي تعترض تطبيقه من وجهات نظرهم.

تتلخص الأهمية النظرية فيما يلي:

حداثة المجال الذي تتناوله الدراسة وقلة الدراسات والبحوث التي عالجته، ذلك أنها تبحث فئه في واقع وتحديات استخدام أحدث ما توصلت إليه تكنولوجيا الاتصالات في مجال تطوير وتحسين العملية التعليمية التعلمية.

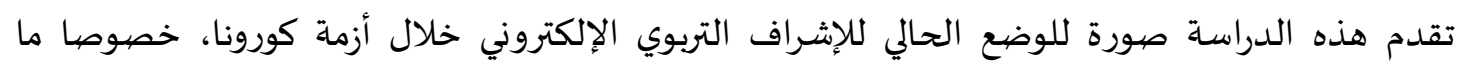

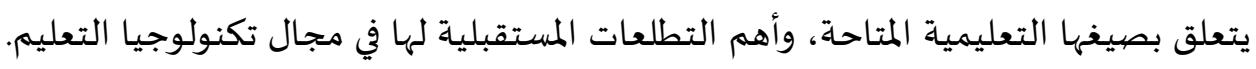
يمكن أن يضيف هذا البحث معرفة جديدة للباحثين وإطار نظري جديد حول الإشراف التربوي الإلكتروني في حالات الطوارئ، ونتائج تطبيق الإشراف الإلكتروني عمليا.

ثانيا: الأهمية التطبيقية: إ يستمد البحث أهميته كونه معاصرا لظاهرة واقعية وهي انتشار فيروس كورونا، ويمكن الاستفادة من نتائج هذه الدراسة في ظواهر طارئة أخرى. ويتوقع من خلال نتائج الدراسة الحالية أن يفيد على النحو الآتي: معرفة واقع استخدام الإشراف الإلكتروني في المدارس الحكومية، وأن تسهم في لفت أنظار الباحثين لإجراء

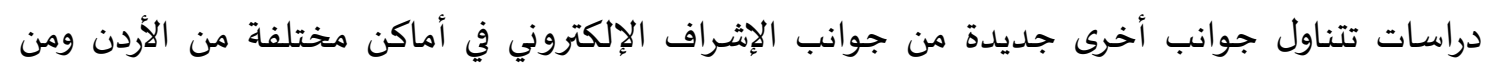

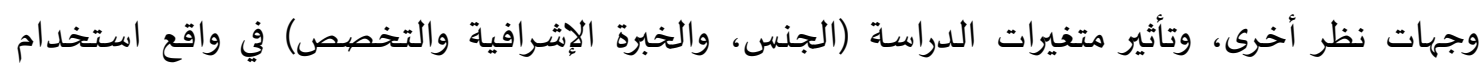
الإشراف الإلكتروني. كما تتوقع الباحثة أن تفيد في توجيه أنظار المسئولين ومتخذي القرار لأهمية استخدام الإشراف الإلكتروني

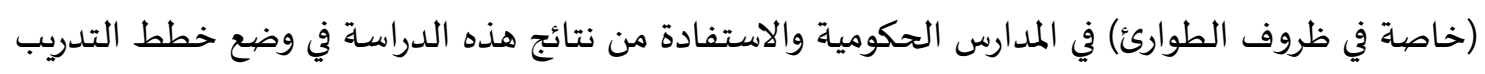
والتطوير بما يخدم عملية الإشراف التربوي لتحقيق الأهداف التي وضيع لأجلها. وتتوقع أن تساعد نتائج الدراسة المسؤولين في التغلب على معوقات تطبيق الإشراف الإلكتروني.

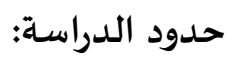
هالحدود الموضوعية: واقع تطبيق الإشراف الإلكتروني في المدارس الحكومية خلال فترة جائحة كورونا

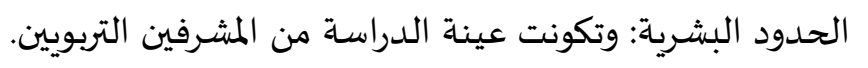
الحدود المكانية: جميع مديريات التربية والتعليم في إقليم الشمال بالأردن. هالحدود الزمنية: هاية الفصل الأول للعام الدراسي (2020- 2021).

مصطلحات البحث وتعريفاته الإجرائية:

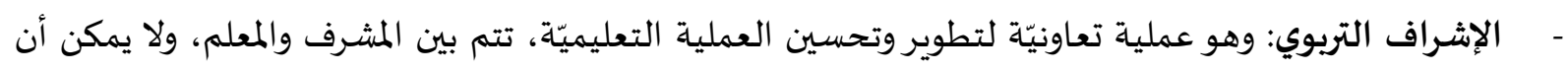

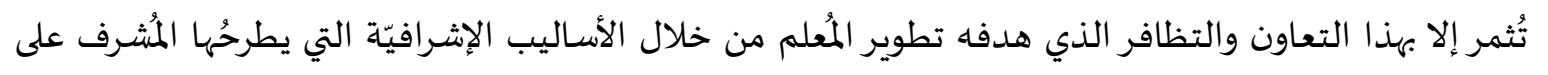


المعلم لتحقيق أكبر قدر من الفائدة للعمليّة التربويّة، ويُعرفه العلماء التربويون بأنّه تحريك وتحديد لمسار

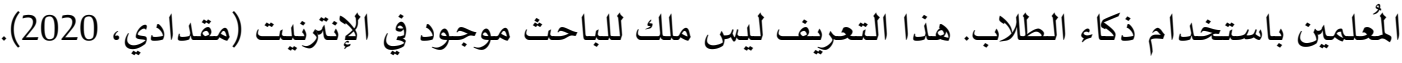
O وتعرفه الباحثة أنه العمل الذي يقوم باه المشرف التربوي لتقديم العون والمساعدة والمتابعة المستمرة

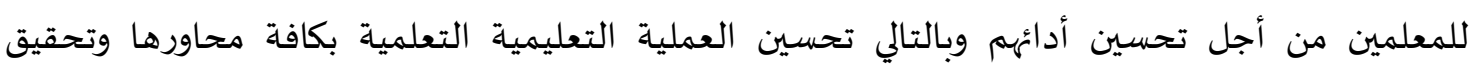
أهدافها المرجوة.

المشرف التربوي: هو خبير فني، وظيفته الرئيسة مساعدة المعلمين على النمو المهني، وحل المشكلات التعليمية

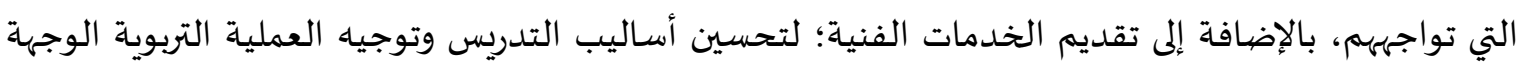
الصحيحة. تعريف موجود في الإنترنت (الصايغ، 2009).

O متعرفه الباحثة: أنه شخص متخصص، مؤهل، مدرب، موجهاه، وهو المسؤول عن تحسين وتطوير العملية

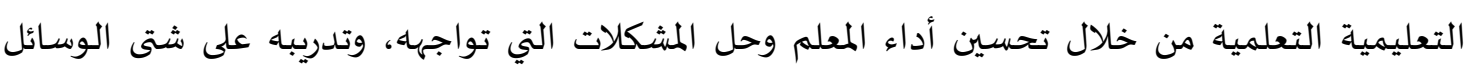

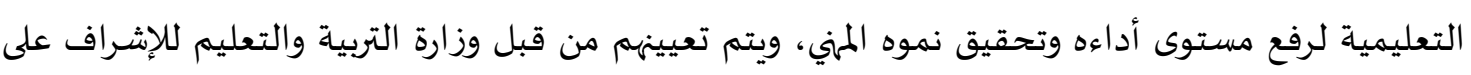
المعلمين. الإشراف الإلكتروني: هو نمط إشرافي يقدم أعمال ومهام الإشراف التربوي عبر تكنولوجيا المعلومات والاتصالات

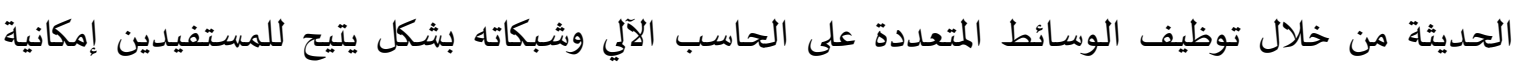

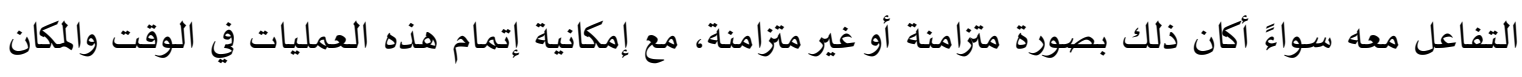

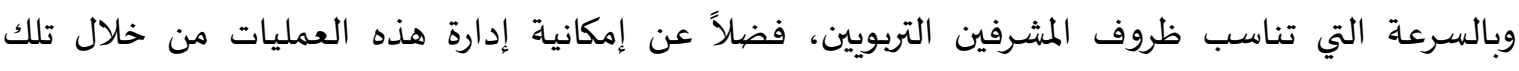

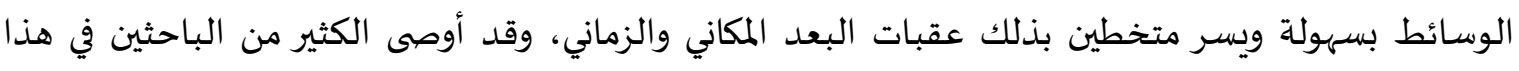

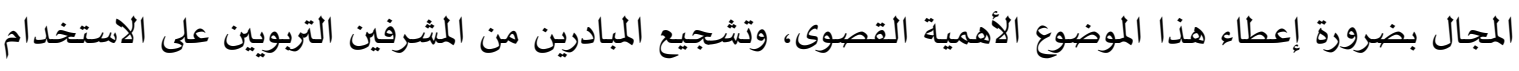

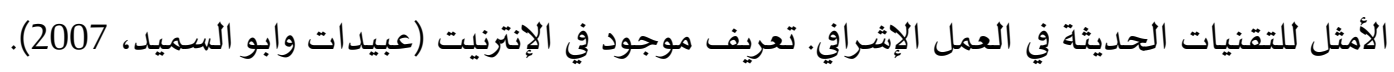

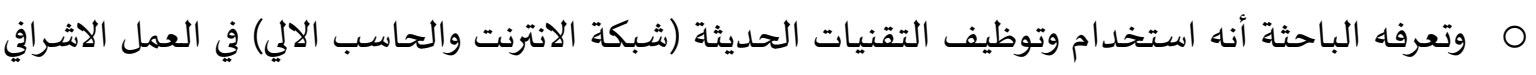

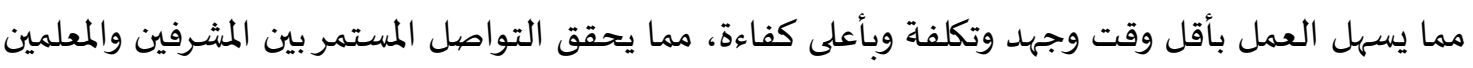
وبالتالي المساعدة في رفع مستوى أدائهم.

2. - 2 الإطار النظري والدراسـات السابقة.

أولا: الإطار النظري:

يتميز هذا العصر بالتغيرات السريعة الناجمة عن التقدم العلمي وتقنيات المعلومات لذا أصبح من الضروري

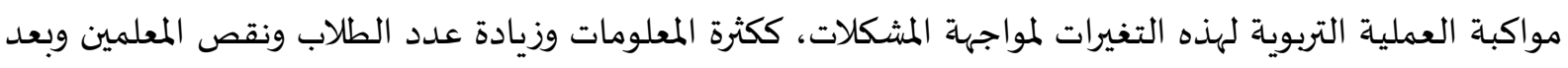

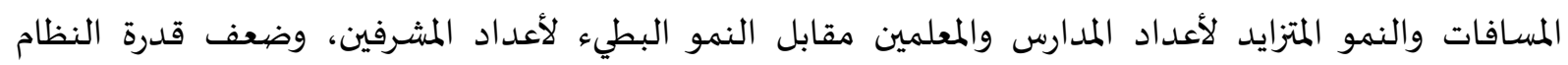

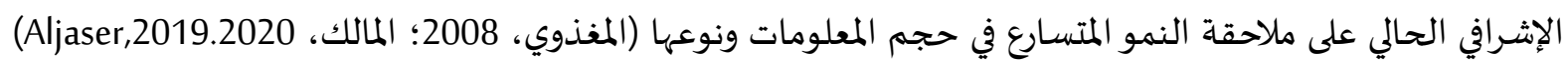

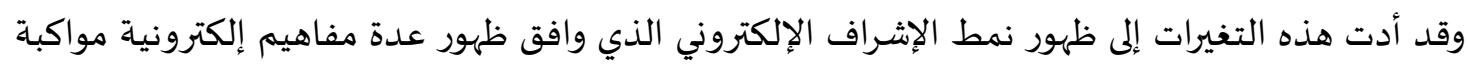

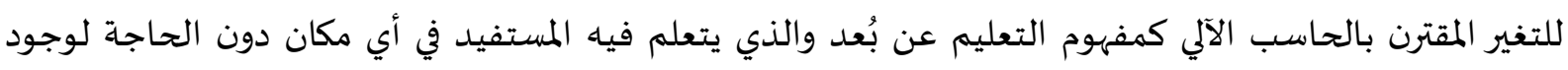

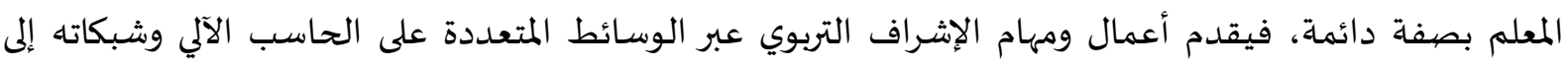

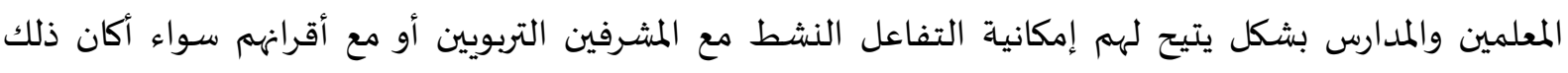

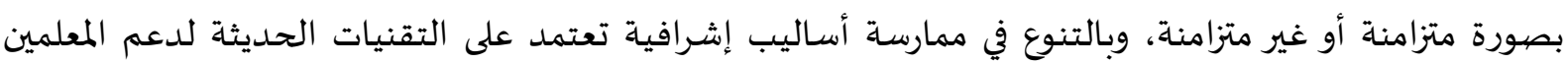


وتنميتهم مهنيا وتطوير العملية التربوية باستخدام الأساليب الإشرافية الحالية من اجتماعات ورسائل ودروس

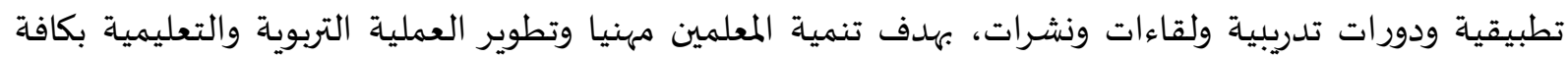

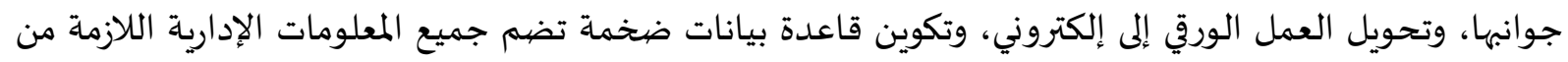

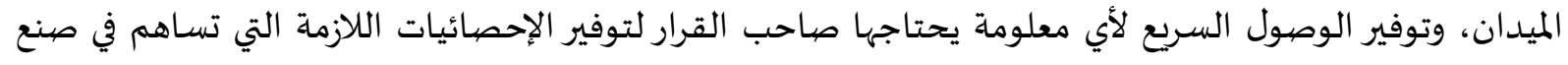

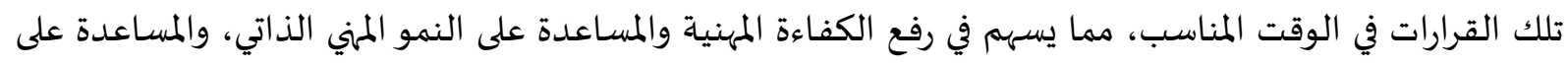

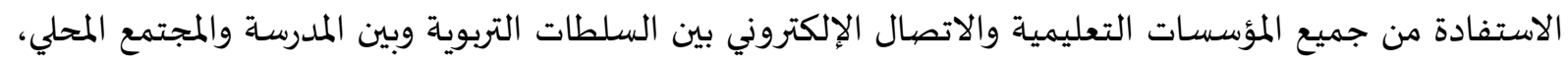

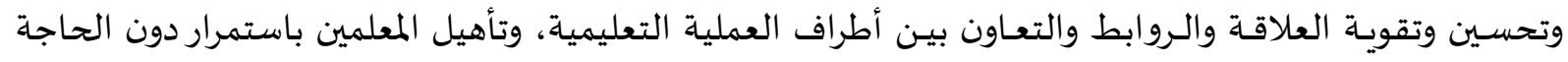

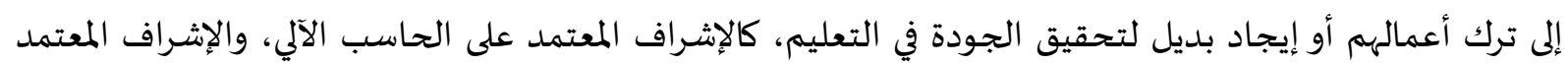

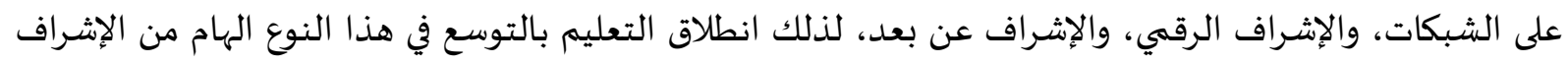

يعد من متطلبات اقتصاد المعرفة والجودة في التعليم (المالك، 2020؛ Draissi,2020).

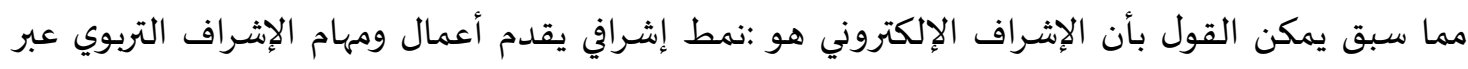

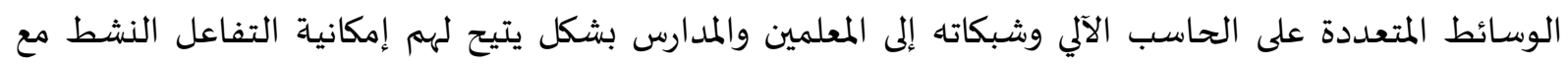

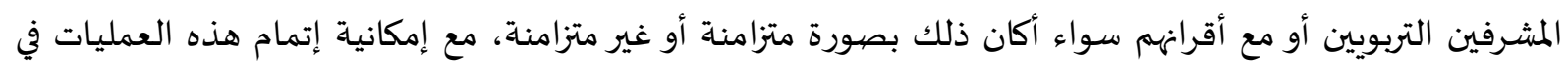

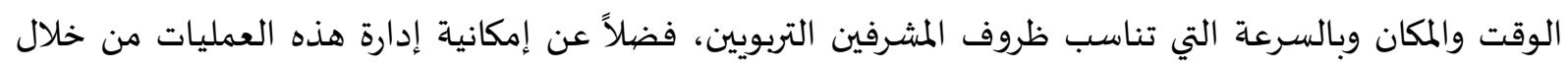

$$
\text { تلك الوسائط (عبد الرحمن، 2019). }
$$

$$
\text { أهداف الإشراف الإلكتروني : }
$$

يسعى الإشراف الإلكتروني إلى تحقيق أهداف الإشراف التربوي التي سبق تحديدها، ولكونه يُمارس بأساليب

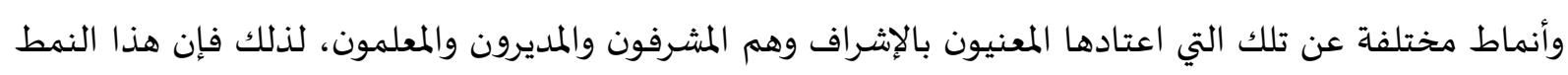

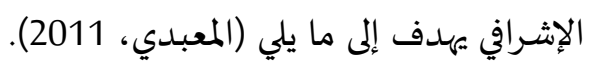
1- تعريف المشرفين بالطرق التربوية الجديدة والاتجاهات الحمديدية الحديثة في الإدارة والمناهج الدراسية والوسائل التعليمية وأساليب التقويم من خلال برمجيات الحاسب. 2- رفع الكفاءة المهنية لهم ومساعدة المشرفين على النمو المهني الذاتي. 3- احترام شخصية المشرفين حتى يصبحوا قادرين على توجيا أنفسهم وتحديد مشكلاتهم وتحليلها.

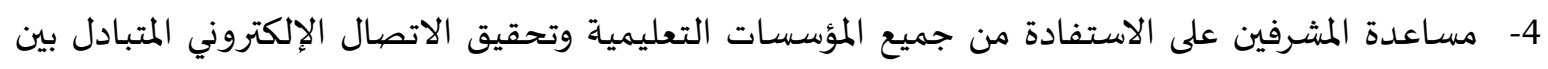
السلطات التربوية وبين المدرسة والمجتمع المحلي. 5- تحسين وتقوية العلاقة والروابط والتعاون فيما بينهم من جهاة وفيما بينهم وبين أقرانهم من جها ألماتية أخرى.

مميزات الإشراف الإلكتروني (Favale et al., 2020) يساعد الإشراف الإلكتروني المعلمين على النمو المهني في أي وقت وفي أي مكاف الإن المان

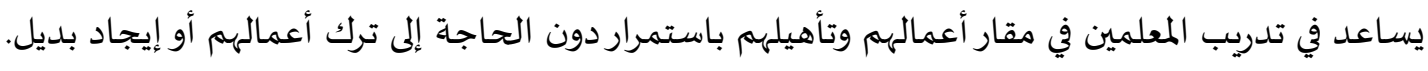
يساعد على تنمية قدرات المعلمين على التواصل مع بعضهيه أو مع أقراههم.

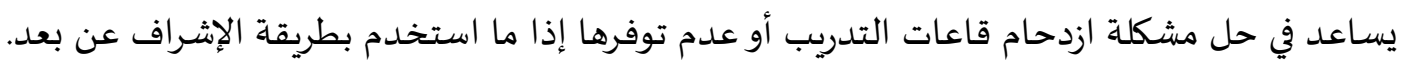

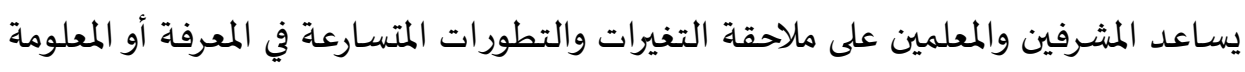

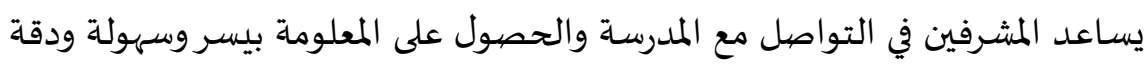

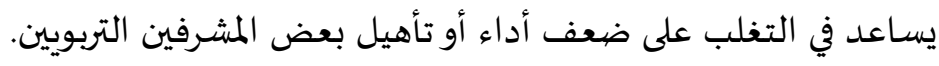


يساعد في الحد من ميل بعض المشرفين للممارسات التفتيشية. يسهم الإشراف الإلكتروني في تحقيق الجودة في التعليم.

معوقات الإشراف الإلكتروني

ل ضعف البنية التحتية لهذا النمط الإشرافي من حيث تأمين الأجهزة والشبكات وأساليب الاتصالات الحديثة

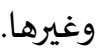

ل عدم كفاية الكوادر البشرية المؤهلة تأهيلاً عالياً لإنجاح هذا النمط سواء الكوادر الفنية (مصممي البرامج،

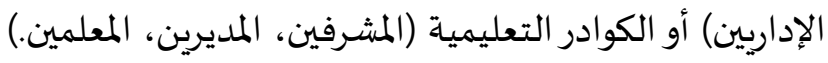

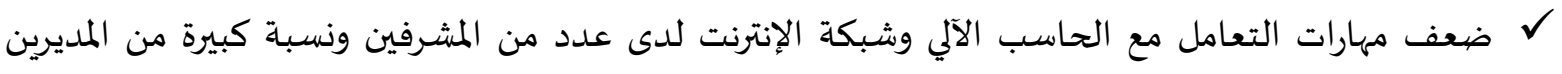

والمعلمين.

ل ارتفاع الكلفة المادية لتطبيق هذا النمط سواء من حيث شراء الأجهزة والبرمجيات أو الاتصال بشبكة الإنترنت.

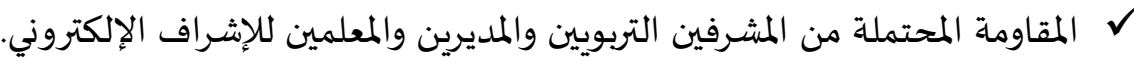

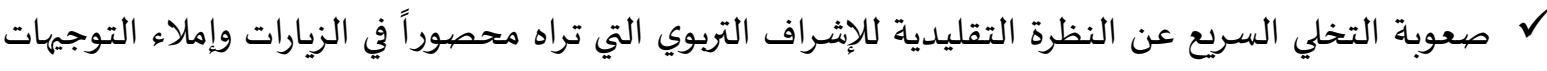

وتقويم الأداء الوظيفي.

ومن هنا تستخلص الباحثة مما سبق، أن الإشراف التربوي من الأركان الرئيسة والفاعلة في النظام التعليمي

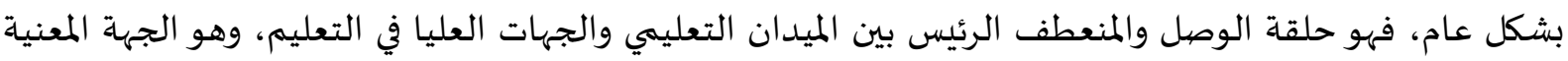
بتشخيص الواقع الفعلي للعملية التعليمية من حيث المدخلات والممارسات والمخرجات، وأيضا يعمل على المئل التحسين

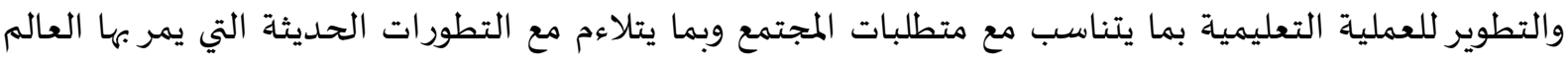

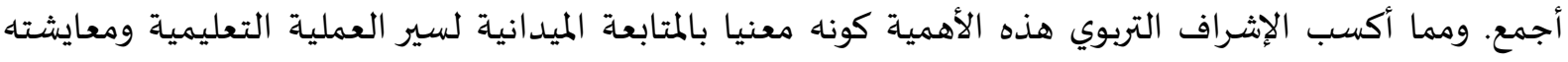

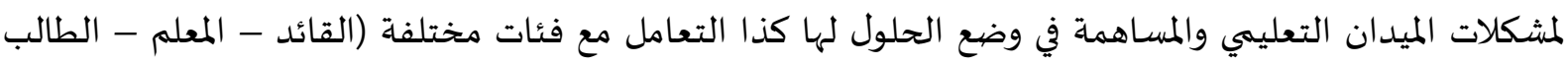

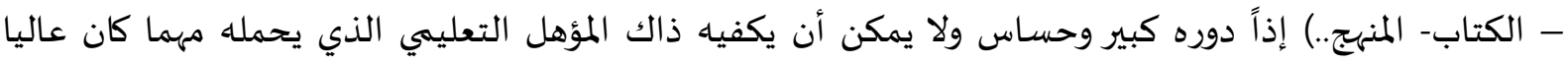

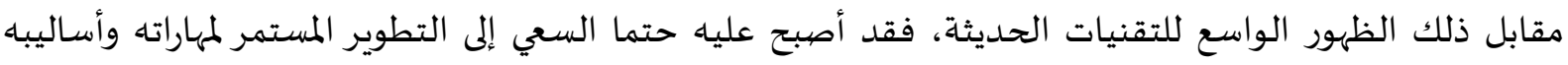

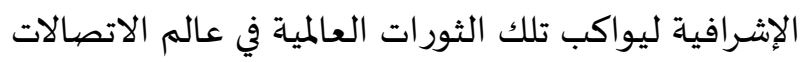

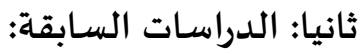

اطلعت الباحثة على العديد من الدراسات في جوانب متعددة من الإشراف التربوي الإلكتروني للاستنارة

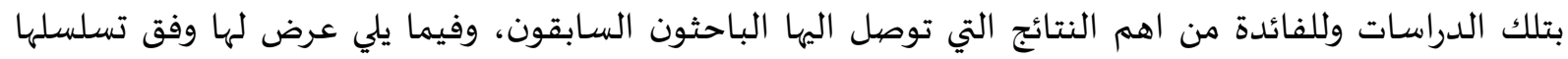
التاريخي من الاقدم إلى الاحدث.

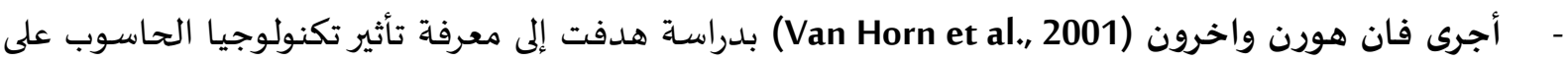

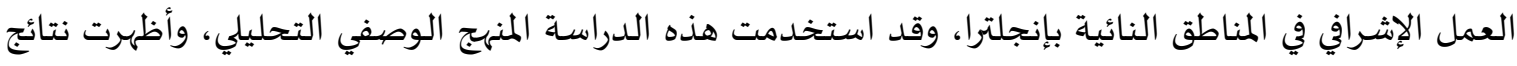
الدراسة تأثير تكنولوجيا الحاسوب على خدمة الإشراف التربوي من خلال إيصال المعلومات والتعاميم للمعلمين

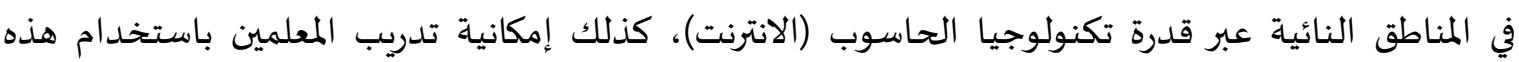

التكنولوجيا.

قام كاربون ورجبسون (Carboni and Riggsbee2007) بدراسة هدفت إلى إنشاء جمعية تعلم عبر الانترنت

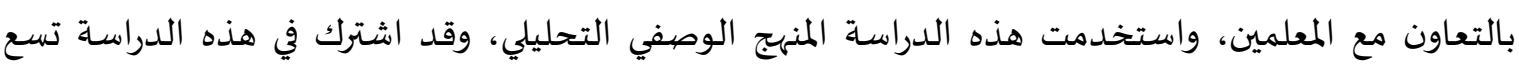

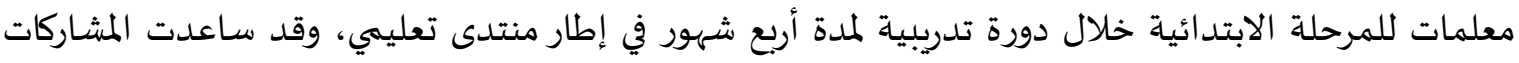


الجيدة للمعلمين من خلال المنتدى في تدعيم إجراءات وتطبيقات الدراسة. كما أوجدت الدراسة تسهيلات كبيرة للمشاركة بالراي والاقتراح على مدار مدة الدراسة كما عنيت بالتفاعل الاجتماعي بين المعلم وأولياء الأمور.

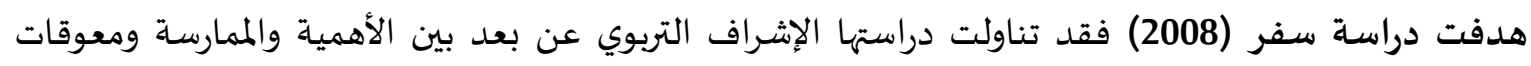

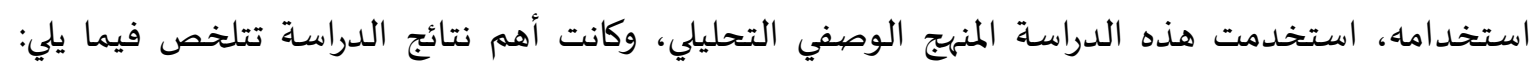

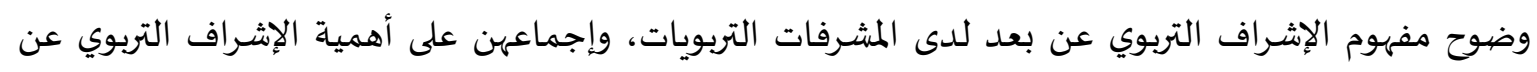

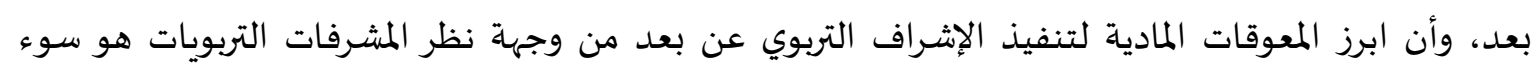

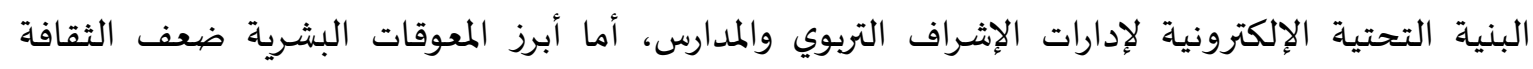

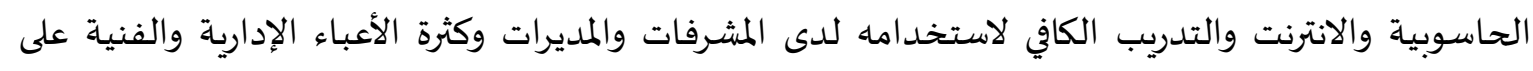

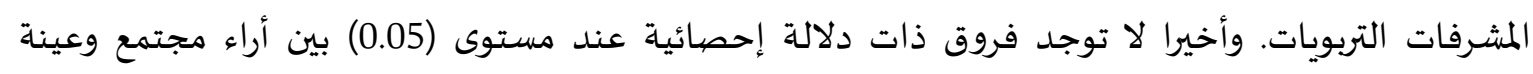

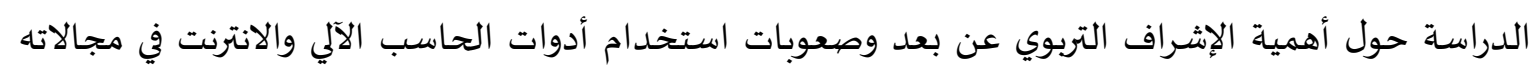
وأساليبه تبعا للمتغيرات: التخصص العرلمي الاشي واختلاف الإجادة في استخدام الحاسب والانترنت.

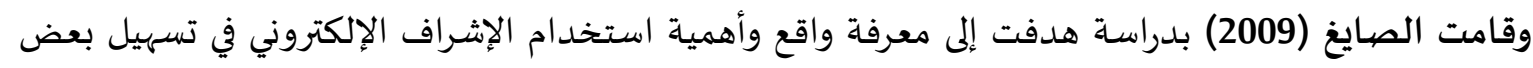

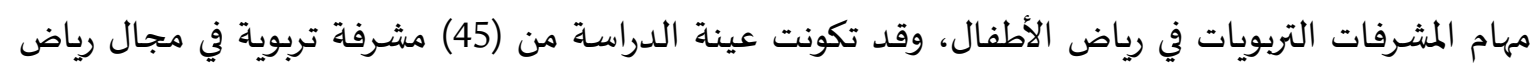

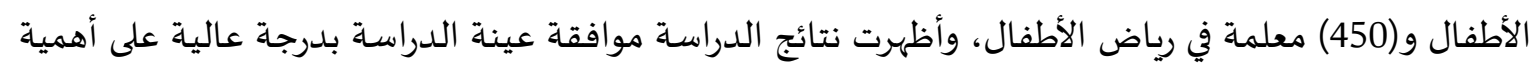

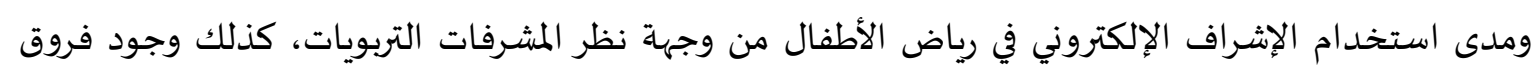

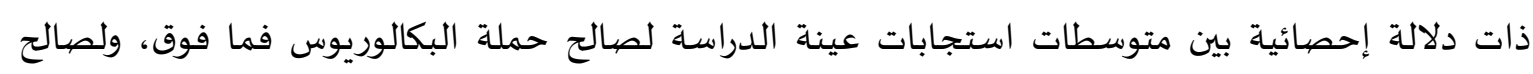
اللاتي لديهن دورات تدربية. اما دراسة الغامدي (2010) تناولت أهمية ومعوقات الإشراف الإلكتروني باستخدام نظم التعليم الإلكتروني

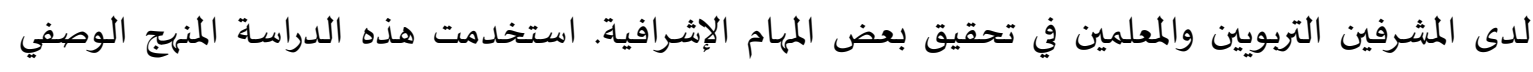

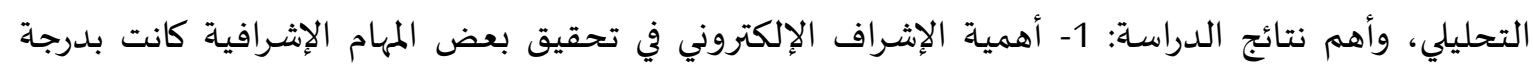

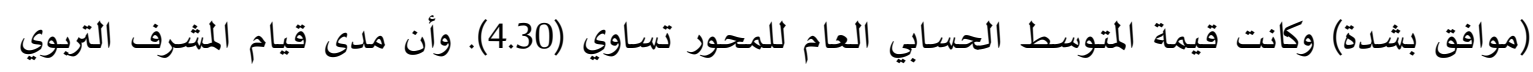

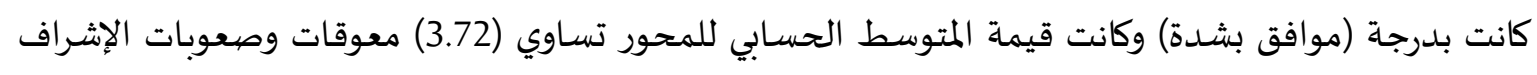

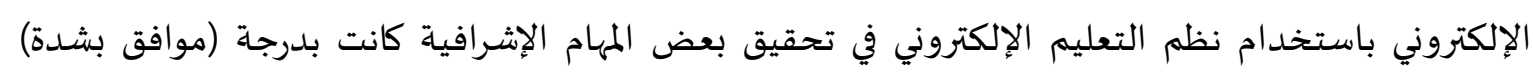

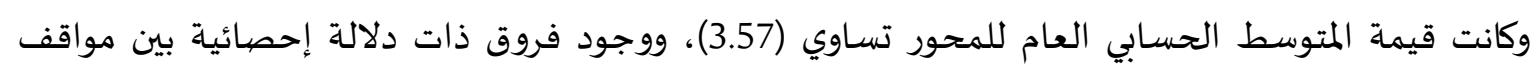

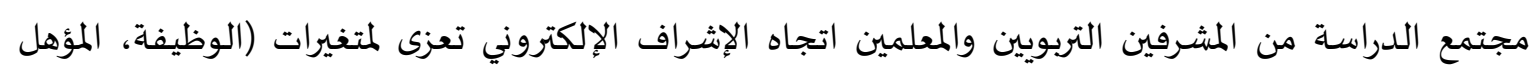

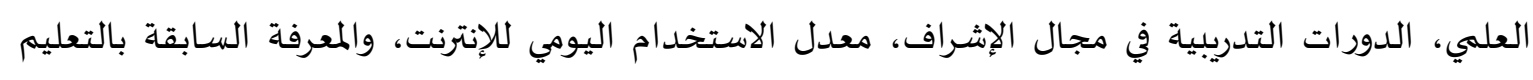

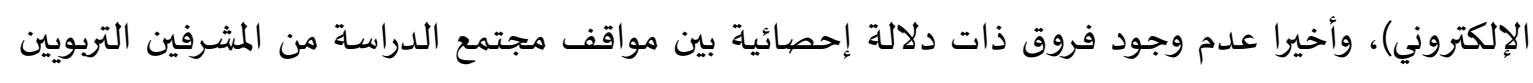

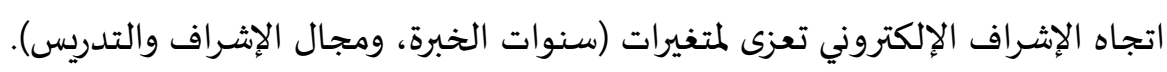

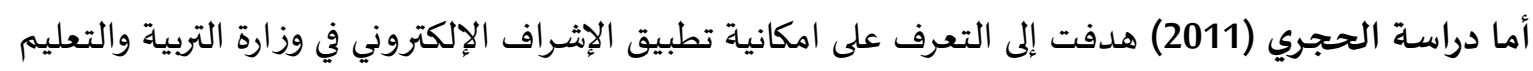

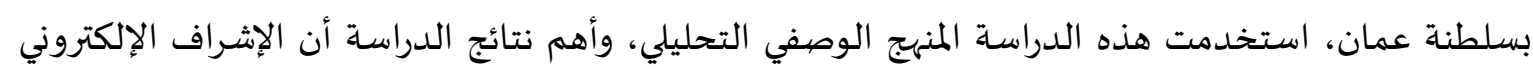

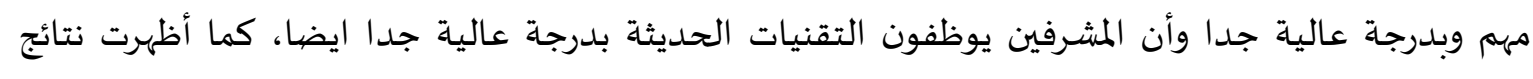

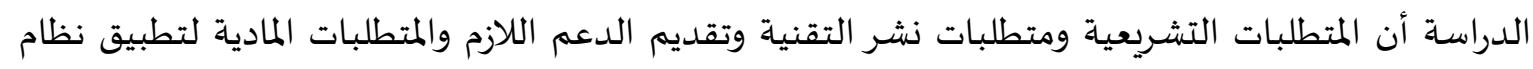

الإشراف الإلكتروني تمثل مطلبا مهما وبدرجة كبيرة جدا.

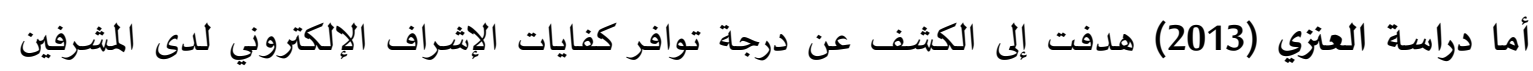

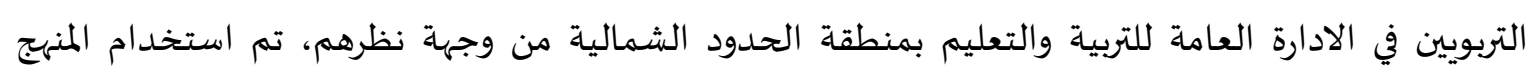


الوصفي التحليلي وقد أظهرت نتائج الدراسة أن كفايات الإشراف الإلكتروني لدى المشرفين التربويين تتوافر

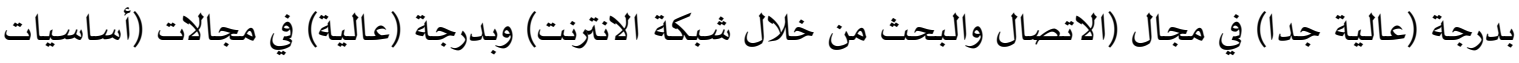

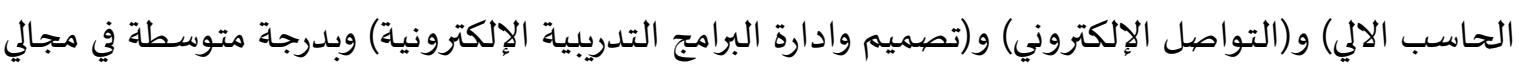
(التقنيات الحديثة للتعلم الإلكتروني) و(التقويم الإلكتروني). هدفت دراسة عبد الرحمن (2019) إلى التعرف على درجة جاهزية وزارة التربية والتعليم الأردنية لتطبيق الإليق

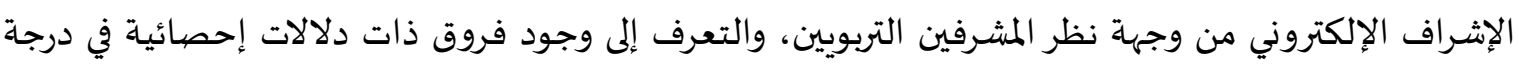

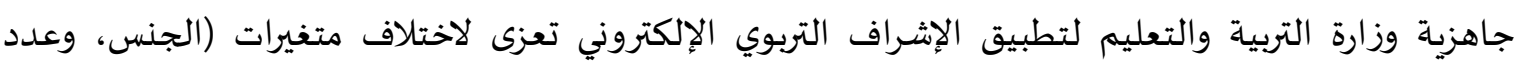

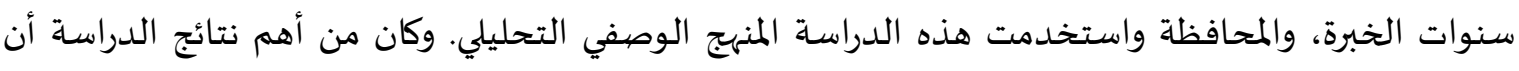

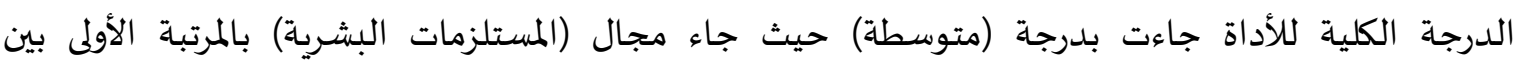

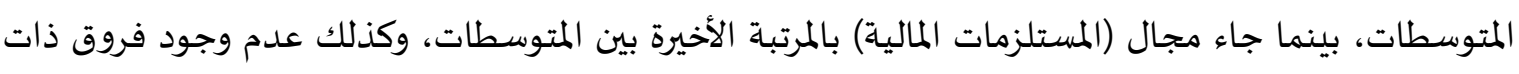
دلالة إحصائية تعزى للمتغيرات مجتمعاءة. دراسة (Aljaser,2019) التي هدفت إلى التعرف على فاعلية بيئة التعلم الإلكتروني في تطوير التحصيل الأكاديمي

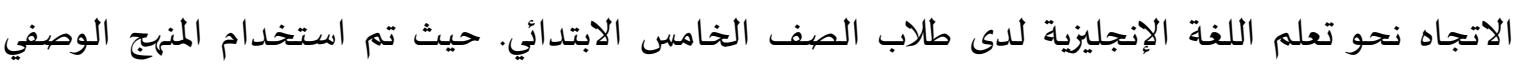

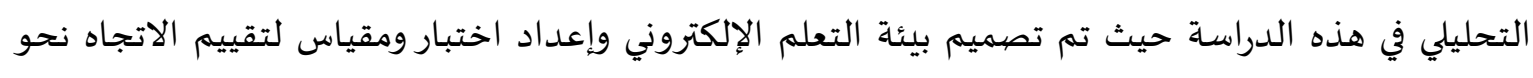

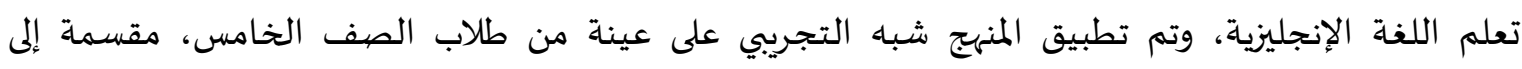

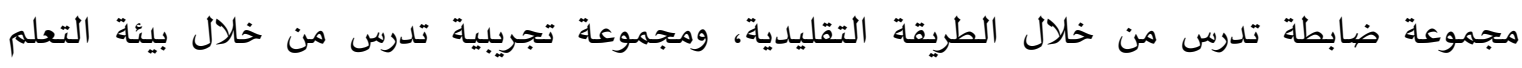

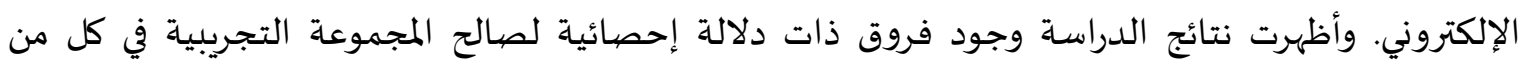
اختبار ما بعد التحصيل ومقياس الاتجاه نحو تعلم اللغة الإنجليزية. وأجرى (Hodge et al, 2020) دراسة هدفت إلى الكشف عن الفرق بين التدريس عن بعد في في حالات الطوارئ والتعليم عبر الانترنت، حيث قام الباحثون بتصميم نموذج مكون من شروط تقاس تقييم ومجموعة من الأسئلة التي

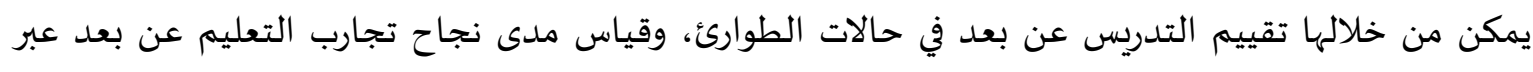

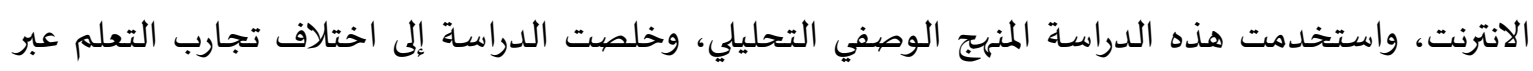

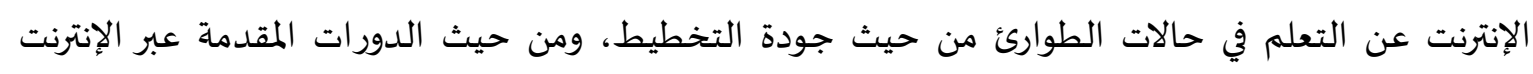

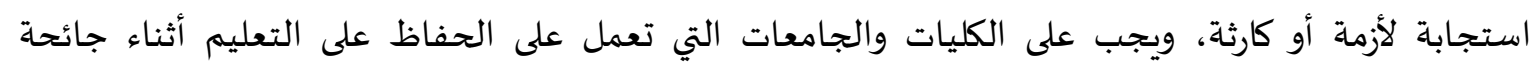

.COVID- 19

وتناولت دراسة الشربيني (2020) إمكانية استخدام الإشراف الإلكتروني في التدريب الميداني في الخدمة

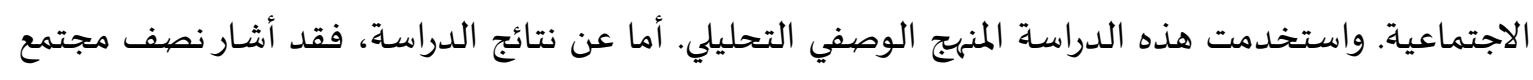

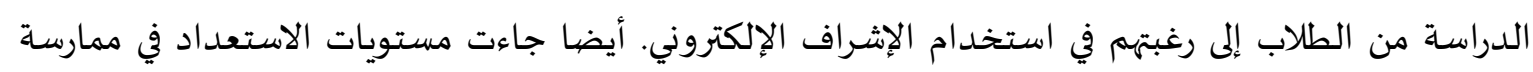

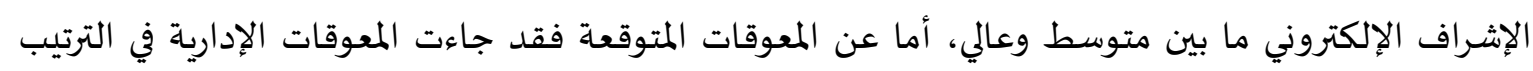
الأول ثم المعوقات الاجتماعية ويليها المعوقات البشرية وأخيرا المعوقات المعات الفنية.

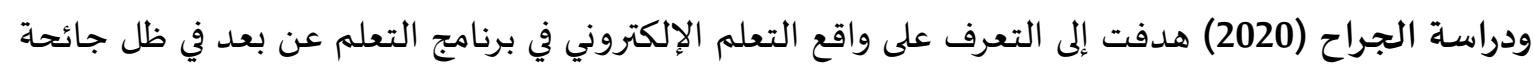

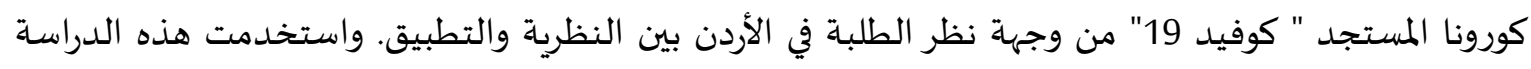

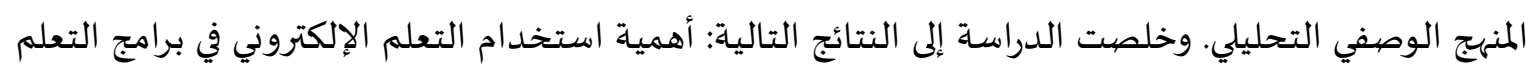
عن بعد. مدى استخدام التعلم الإلكتروني في برامج التعلم عن بعد. هناك صعوبة تحول دون استخدام التعلم 


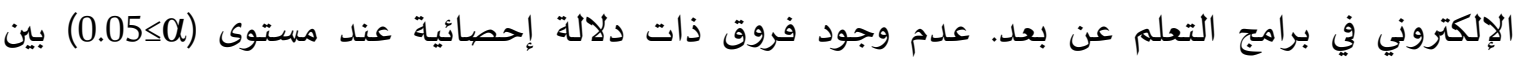

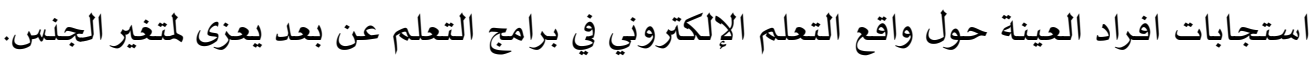
أما دراسة أبوقوطة والدلو (2020) هدفت إلى الكشف عن فاعلية التعليم الإلكتروني في ظل جائحة كولئ كورونا

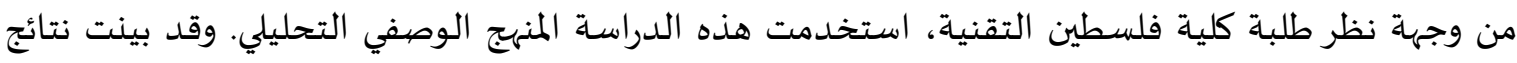
الدراسة حصول مجال فعالية التقييم الإلكتروني المستخدم في الكلية من وجهاة نظر الطلبة على الترتيب الأول

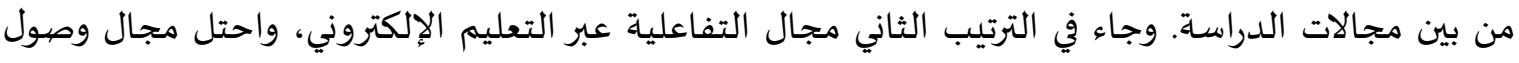
الطلبة للتعليم الإلكتروني الترتيب الثالث في حين جاء في الترتيب الرابع مجال فعالية التدريس عبر التعليم الإلكتروني.

استهدفت دراسة أبو حسين (2021) التعرف على معوقات ممارسة الإشراف الإلكتروني من وجهة نظر

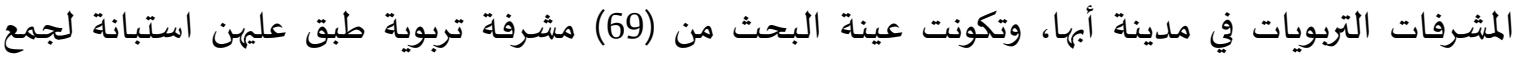

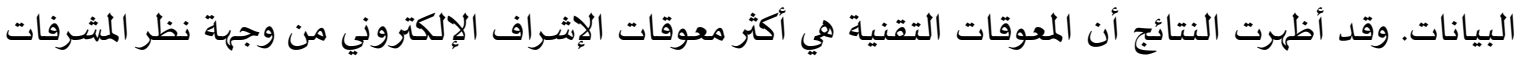

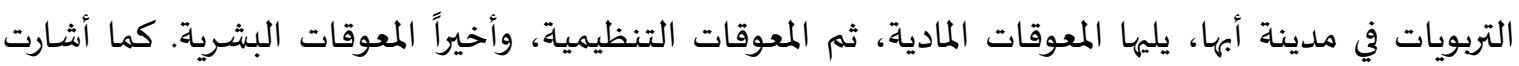

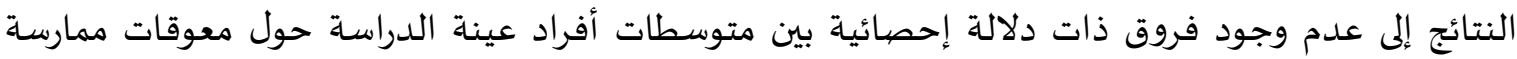
الإشراف الإلكتروني تعزى لمتغيري التخصص والمؤهل، بينما توجد فروق تعزى لمتغير سنوات الخبرة.

التعقيب على الدراسات السابقة: من العرض السابق الدراسات السابقة فقد أشارت إلى ضعف الثقافة الحاسوبية لدى أفراد العينة وندرة

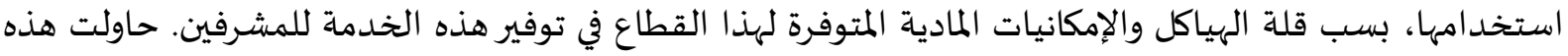
الدراسة أن تضيف إلى نتائج الدراسات السابقة من خلال الكشف أكثر طبيعة استخدام الإشراف الإلكتروني من وجهة نظر المشرفين التربويين. بحثت الدراسات السابقة في درجة جاهزية وزارة التربية والتعليم الأردنية لتطبيق الإشراف الإلكتروني من وجهة نظر المشرفين التربويين (عبد الرحمن، 2019)، وامكانية تطبيق الإشراف الإلكتروني في وزارة التربية والتعليم بسلطنة عمان (الحجري، 2011)، والى الكشف عن درجة توافر كفايات الإشراف الإلكتروني لدى المشرفين الإنين التربوينين

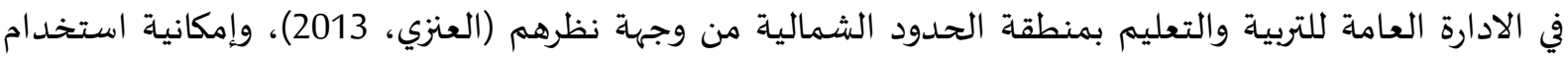

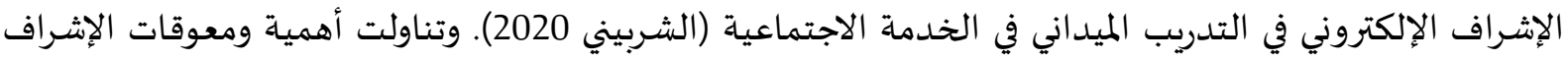

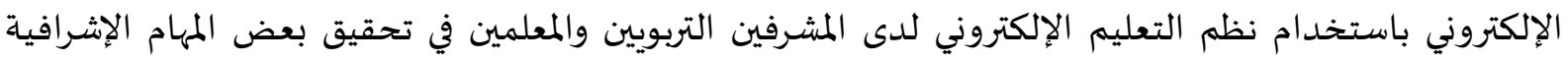

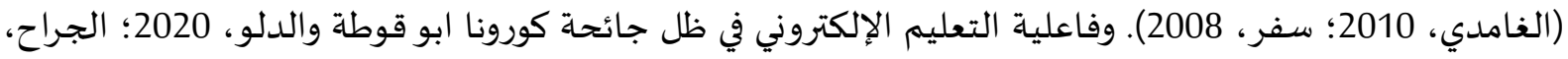

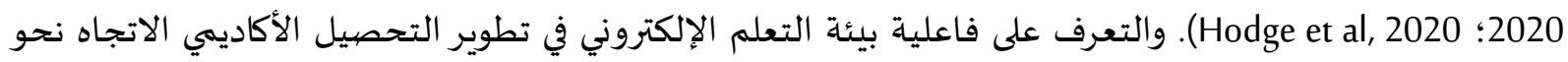
تعلم اللغة الإنجليزية لدى طلاب الصف الخامس الابتدائي (Aljaser,2019). تتشابه هذه الدراسة مع الدراسات في تحدهها عن الإشراف التربوي الإلكتروني واعتمادها على المنهج

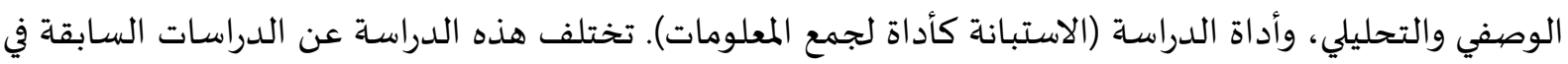

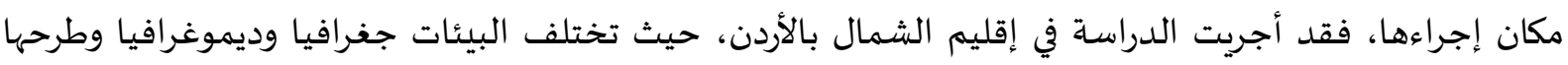

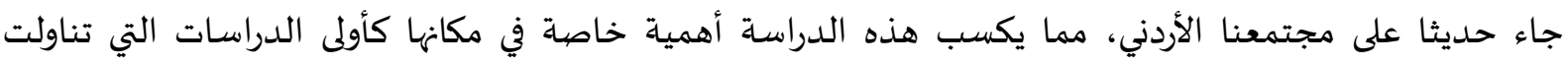

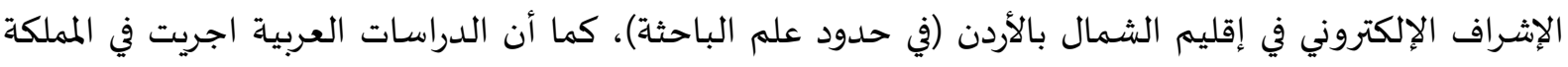

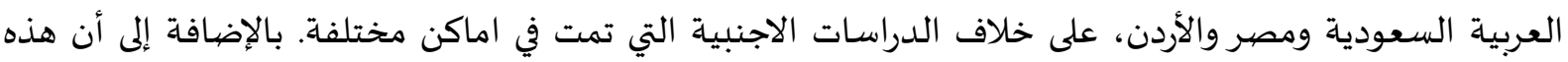


الدراسة تتميز عن الدراسات السابقة في تناولها دراسـة واقع تطبيق الإشراف التربوي الإلكتروني في ظروف طارئة (انتشار فيروس كورونا). وقد استفادت الباحثة من الدراسات السابقة في الإطار النظري، وبناء الاداة (الاستبانة) ومناقشة النتائج.

مما سبق يتضح أن الدراسات السابقة ركزت على ضرورة المشرفين التربويين الإشراف الإلكتروني المتمثل

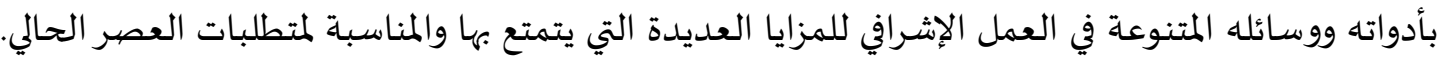
3. منهجية الدراسة واجراءاتها:

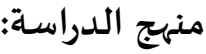
اعتمدت الباحثة المنهج الوصفي التحليلي لجمع البيانات باعتباره الأكثر توافقا مع أهداف وإجراءات وطبيعة

يتكون مجتمع الدراسة من جميع المشرفين في إقليم الشمال بالأردن وعددهم (248) مشرف ومشرفة.

عينة الدراسة: أجريت الدراسة على عينة قوامها (50) مشرف ومشرفة من تخصصيات مختلفة في إقليم الشمال بالأردن في الأردن وهي تشكل ما نسبته (20.1\%) من أفراد المجتمع الأصلي (وعددهم 248 مشرف ومشرفة) تم اختيارهم بالطريقة العشوائية. والجداول (1) و(2) و(3) تبين توزيع عينة الدراسة تبعا لمتغيراتها المستقلة. جدول (1) توزيع عينة الدراسة تبعا لمتغير الجنس عانس تورانه

\begin{tabular}{|c|c|c|}
\hline النسبة & التكرار & النوع \\
\hline$\% 41$ & 21 & ذكر \\
\hline$\% 59$ & 29 & أنثى \\
\hline$\% 100$ & 50 & المجمموع \\
\hline
\end{tabular}

جدول (2) توزيع عينة الدراسة تبعا لمتغير الخبرة الإشرافية

\begin{tabular}{|c|c|c|}
\hline النسبة & التكرار & الخبرة الإشرافية \\
\hline$\% 80$ & 39 & أقل من 5 سنوات \\
\hline$\% 7$ & 4 & من 5 - 10سنوات \\
\hline$\% 13$ & 7 & أكثر من 10سنوات \\
\hline$\% 100$ & 50 & المجمووع \\
\hline
\end{tabular}

جدول (3) توزيع عينة الدراسة تبعا لمتفير التخصص

\begin{tabular}{|c|c|c|}
\hline النسبة & التكرار & التخصص \\
\hline$\% 33$ & 33 & التخصصيات العلمية \\
\hline$\% 67$ & 17 & التخصصيات الادبية \\
\hline$\% 100$ & 50 & المجموع \\
\hline
\end{tabular}


اعتمدت الدراسة على استبانة إلكترونية لتقييم مدى تطبيق الإشراف التربوي الإلكتروني في ظل جائحة

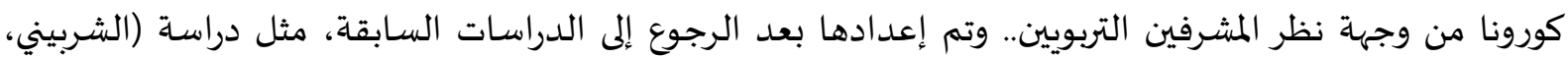

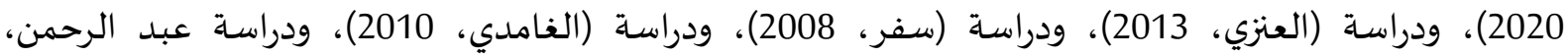

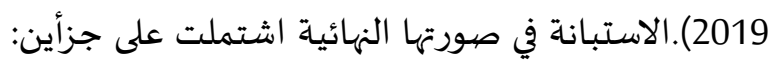

$$
\text { الجزء الأول: يشمل المعلومات الأولية }
$$

عن المشرف التربوي الذي قام بتعبئة الاستبانة، وهي معلومات عامة وهي: الجنس، وسنوات الخبرة الإشرافية، والتخصص.

الجزء الثاني: يتكون من 37 فقرة، موزعة على (4) مجالات فيما يتعلق بواقع استخدام الإشراف الإلكتروني في المدارس الحكومية من وجهة نظر المشرفين التربويين في لواء إقليم الشمال بالأردن في الأردن. وهذه المجالات موضحة في الجدول (4).

الجدول (4) توزيع الفقرات على مجالات الدراسة (مقياس ليكرت الخماسي)

\begin{tabular}{|c|c|c|}
\hline الفقرات & عدد الفقرات & المجال \\
\hline $10-1$ & 10 & مفهوم الإشراف الإلكتروني \\
\hline $22-11$ & 12 & أهمية الإشراف الإلكتروني \\
\hline $32-23$ & 10 & تطبيق الإشراف الإلكتروني في العلم الإشرافي \\
\hline $37-33$ & 5 & معوقات استخدام الإشراف الإلكتروني \\
\hline \multicolumn{2}{|c|}{37} & المجموع \\
\hline
\end{tabular}

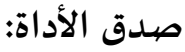

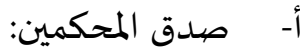

تم عرض الاستبانات على مجموعة من السادة المحكمين من قسم الإشراف التربوي في لواء الأغوار الشمالية

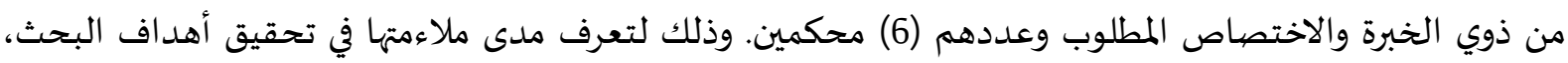

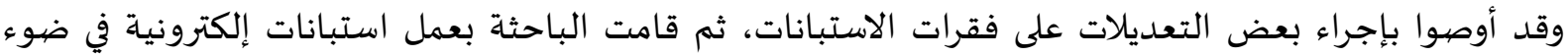
مقترحات السـادة المحكمين وتم توزيعها إلكترونيا.

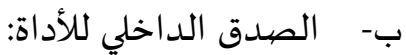
وللتأكد من صدق الاتساق الداخلي تم حساب معامل الارتباط بيرسون بين كل فقرة والدرجة الكلية للاستبانة، وذلك بتطبيق الاستبانات على عينة استطلاعية مكونة من 5 مشرفين من افراد مجتمع الدراسة خارج

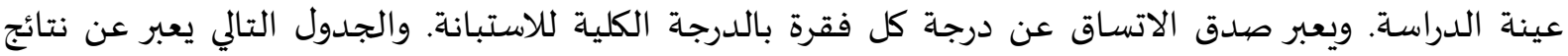
معامل الارتباط لكل فئة من مجتمع الدراسة.

الجدول (5) معاملات ارتباط بيرسون لكل مجال من مجالات الاستبانة والدرجة الكلية للاستبانة

\begin{tabular}{|c|c|c|c|}
\hline معامل الارتباط الاط & 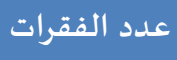 & 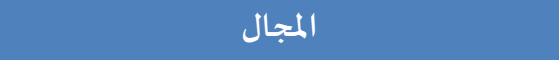 & \\
\hline 0.82 & 10 & مفهوم الإشراف الإلكتروني & 1 \\
\hline 0.81 & 12 & أهمية الإشراف الإلكتروني & 2 \\
\hline 0.81 & 10 & تطبيق الإشراف الإلكتروني في العلم الإشرافي & 3 \\
\hline 0.82 & 5 & معوقات استخدام الإشراف الإلكتروني & 4 \\
\hline
\end{tabular}




$$
\text { دال عند } 0.01
$$

يتضح من الجدول (5) أن قيم معاملات ارتباط بيرسون بين درجة كل مجال من مجالات الاستبانة والدرجة الكلية لها عند مستوى دلالة (0.01) تراوحت بين (0.81- 0.83) وهي قيم تشير إلى الاتساق بين مجالات الاستبانة والدرجة الكلية، مما يعكس درجة عالية من الصيدق بين فقرات مجالات مالات الاستبانة.

ثبات الاداة: - ت ت

للتحقق من ثبات الاداة استخدمت معادلة كرونباخ الفا لاستخراج الثبات كانت نسبته الكلية على فقرات

$$
\text { الاستبانة (0.81) وهي نسبة تؤكد امكانية استخدام الاداة. }
$$

الوزن النسبي:

أعطي للفقرات ذات المضمون الايجابي (5) درجات عن كل اجابة (موافق بشدة) و(4) درجات عن كل اجابة

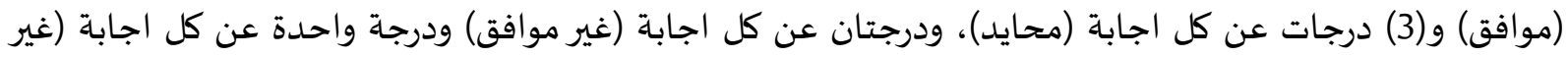

ومن اجل تفسير النتائج اعتمد الميزان الاتي للاستجابات، الجدول (6) الماتئ

\begin{tabular}{|c|c|c|}
\hline التقدير اللفظي & الوزن النسبي & المتوسطات \\
\hline منخفضية جدا & $\% 36-\% 20$ & $1.8-1$ \\
\hline منخفضية & $\% 52$-\%36.2 & $02.6-1.81$ \\
\hline متوسطة & \%68 -\%52.2 & $3.40-2.61$ \\
\hline مرتفعة & \%84 -\%68.2 & $4.20-3.41$ \\
\hline مرتفعة جدا & \%100 -\%84.2 & $5-4.21$ \\
\hline
\end{tabular}

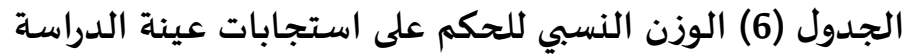

التحليل الاحصيائي:

بعد جمع البيانات تم ادخالها للحاسب لتعالج بواسطة البرنامج الاحصائي للعلوم الانسانية (SPSS)، وقد

استخدمت المتوسطات الحسابية الموزونة والانحرافات المعيارية. واختبار (ت).

\section{4. عرض النتائج ومناقشتها.}

النتائج المتعلقة بالإجابة عن السؤال الأول: ما واقع تطبيق الإشراف الإلكتروني في المدارس الحكومية من

وجهة نظر المشرفين التربويين في إقليم الشمال بالأردن؟ الأبن المابه

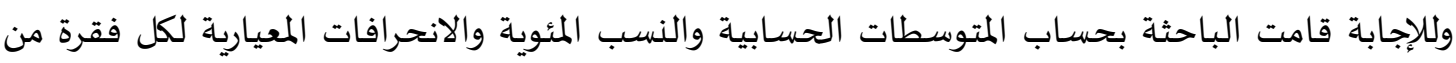
فقرات مجالات الدراسـة. والجدول (7) و(8) يوضح نتائج التحليل الاحصائي للمجالات والدرجات الكلية للاستجابات. 
الجدول (7) المتوسطات الحسابية والانحرافات المعيارية والنسب للمجالات والدرجة الكلية لاستجابات المشرفين التربويين

\begin{tabular}{|c|c|c|c|c|c|}
\hline التقدير & 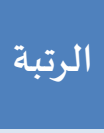 & النسبي & الالمعراف & الحستوسط & 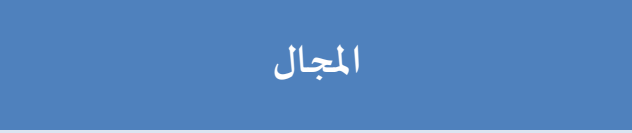 \\
\hline 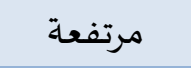 & 4 & $\% 76.0$ & 0.591 & 3.80 & مفهوم الإشـراف الإلكتروني \\
\hline 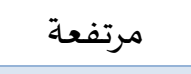 & 2 & $\% 79.6$ & 0.545 & 3.98 & أهمية الإشراف الإلكتروني \\
\hline 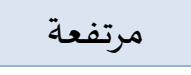 & 3 & $\% 78.2$ & 0.549 & 3.91 & تطبيق الإشراف الإلكتروني في العمل الإشرافي \\
\hline مرتفعة جدا & 1 & $\% 84.2$ & 0.523 & 4.21 & معوقات استخدام الإشراف الإلكتروني \\
\hline 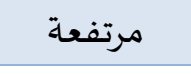 & & $\% 79.6$ & 0.552 & 3.98 & الدرجة الكلية \\
\hline
\end{tabular}

يتبين من الجدول (7) أن واقع تطبيق الإشراف الإلكتروني في المدارس الحكومية من وجهاة نظر المشرفين

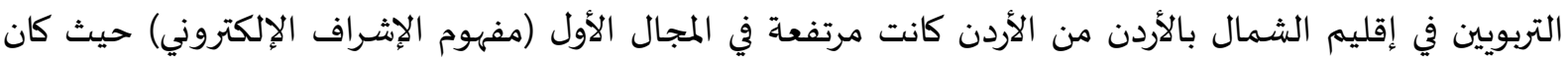
مستوى الاستجابة عليها (3.80) ووزنها النسبي (76\%) ورتبتها (4) وكذلك كانت مرتفعة على الانى المجال الثاني الثاني (أهمية الإشراف التربوي)حيث بلغ المتوسط (3.98) ووزنها النسبي (79.6\%) ورتبتها (2)، ومرتفعة على المجال الثالث (تطبيق

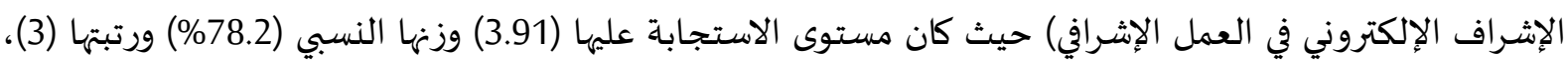
أما المجال الرابع (معوقات استخدام الإشراف الإلكتروني) فكانت مرتفعة جدا ومستوى الاستجابة عليها (4.21) ووزنها النسبي (84.2\%) ورتبتها (1). وتبين الجداول (8) و(9) و(10) و(11) نتائج المتوسطات الحسابية والنسب المئوية والانحرافات المعيارية للمجالات الأربعة الجدول (8) المتوسطات الحسابية والنسب المئوية والانحرافات المعيارية والاوزان النسبية والرتبة والتقدير للمجال الأول (مفهوم الإشراف الإلكتروني)

\begin{tabular}{|c|c|c|c|c|c|}
\hline التقدير & 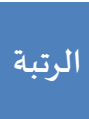 & 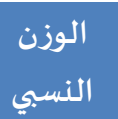 & 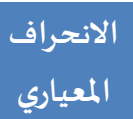 & المتوسط & 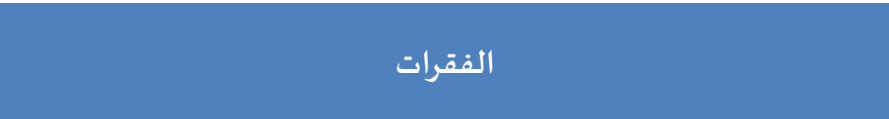 \\
\hline مرتفعة & 9 & $\% 72$ & 0.658 & 3.6 & الإشراف الإلكتروني يفسح المجال للتفاعل النشط بين المشرف والمعلم \\
\hline مرتفعة & 7 & $\% 74.2$ & 0.656 & 3.71 & الإشراف الإلكتروني يتميز بالمرونة والتكيف مع جميع الظروف. \\
\hline 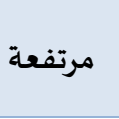 & 8 & $\% 73.6$ & 0.633 & 3.68 & يتم تقديم الخدمات الإشرافية عبر الوسائط المتعددة وشبكة الانترنت \\
\hline مرتفعة & 4 & $\% 69.4$ & 0.655 & 3.47 & فكرة الإشراف الإلكتروني موجودة منذ زمن لكن تم تفعيلها خلال أزمة \\
\hline مرتفعة & 8 & $\% 73.6$ & 0.690 & 3.68 & الإشراف الإلكتروني يسهل عمل المشرف التربوي في التواصل مع المعلمين \\
\hline مرتفعة & 3 & $\% 79.6$ & 0.590 & 3.98 & 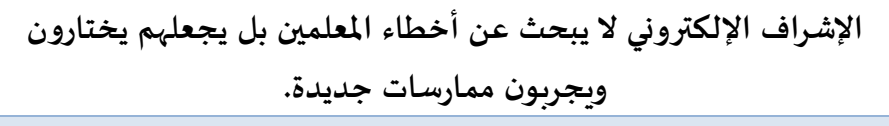 \\
\hline 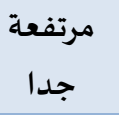 & 1 & $\% 84.6$ & 0.423 & 4.28 & الإشراف الإلكتروني يتطلب تدريب كل من المشرف والمعلم. \\
\hline 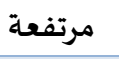 & 2 & $\% 80.2$ & 0.512 & 4.01 & الإشراف الإلكتروني يهدف إلى تسهيل عمل المشرف التربوي \\
\hline 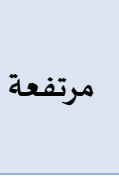 & 6 & $\% 75.6$ & 0.511 & 3.78 & 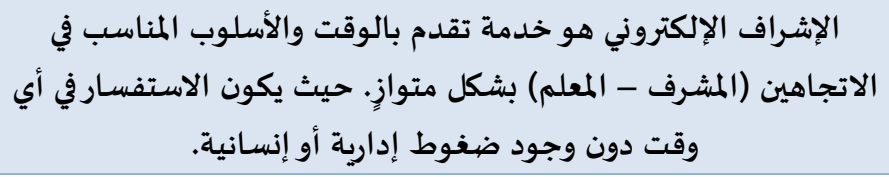 \\
\hline
\end{tabular}




\begin{tabular}{|c|c|c|c|c|c|}
\hline 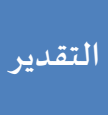 & 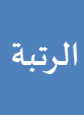 & النسبي & الانحراف & المتوسط & 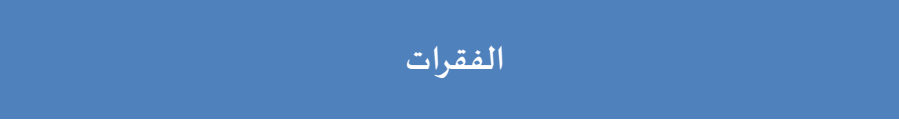 \\
\hline 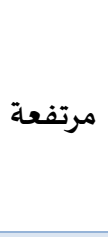 & 5 & $\% 75.8$ & 0.621 & 3.79 & 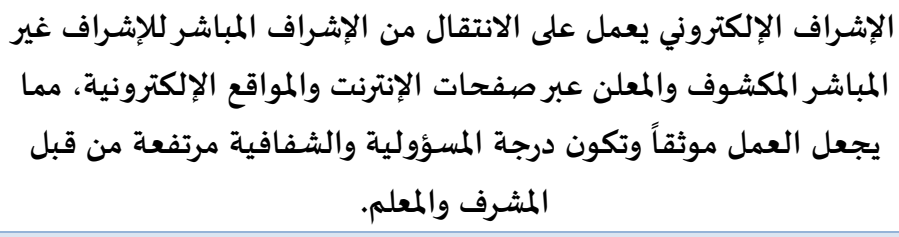 \\
\hline \multicolumn{2}{|c|}{ مرتفعة } & \%76 & 0.595 & 3.80 & الدرجة الكلية \\
\hline
\end{tabular}

يتبين من الجدول (8) السابق واقع تطبيق الإشراف الإلكتروني في المدارس الحكومية من وجهات نظر

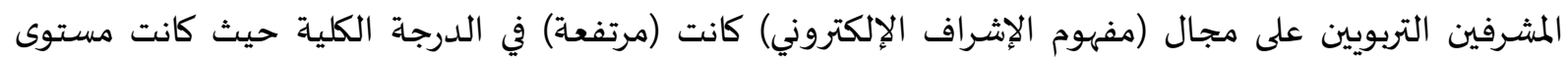

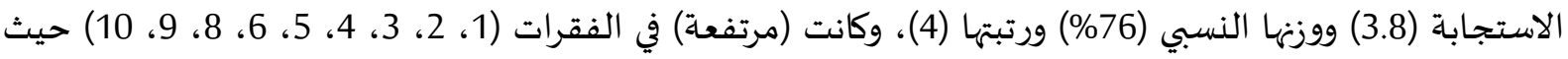

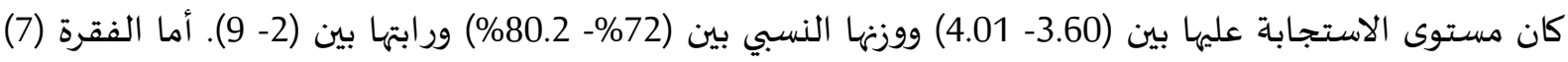

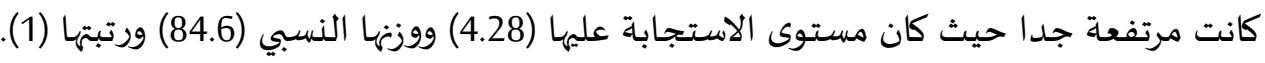

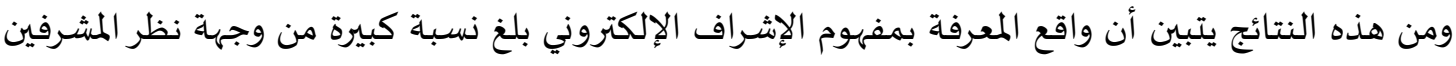

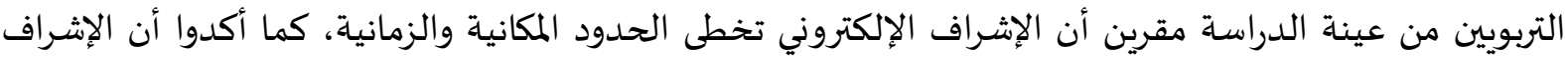

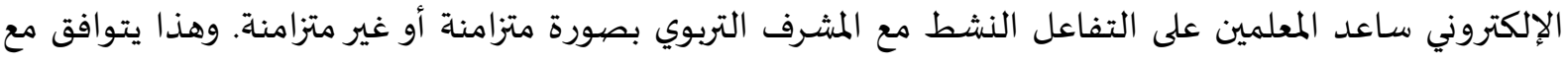

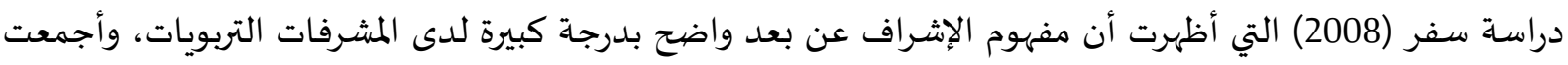
المشرفات بضرورة تطبيقه بدرجة كبيرة لتتناسب مع متطلبات العصر الحديث. ودراسة (Van Horn\& Others, 2001) التي أثبتت مدى قدرة تكنولوجيا الحاسب وتوظيفها في خدمة الإشراف التربوي الإلكتروني وذلك بإيصال المعلومات

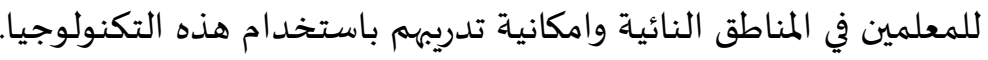

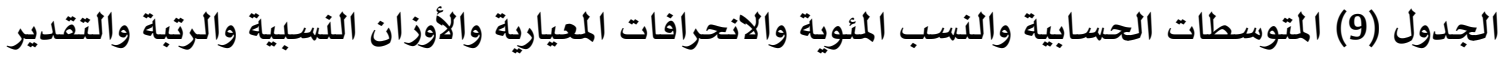
للمجال الثاني (أهمية الإشراف الإلكتروني)

\begin{tabular}{|c|c|c|c|c|c|}
\hline التقدير & الرتبة & الالنسبية & الالتحراف المياري & المتوسط الحسابي & الفقرات \\
\hline مرتفعة & 12 & \%73.2 & 0.623 & 3.66 & الإشراف الإلكتروني يساعد المعلم في الوصول إلى مكتبة تثري ثقافته وترفع من \\
\hline 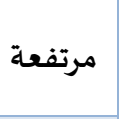 & 8 & \%74.8 & 0.596 & 3.74 & $\begin{array}{c}\text { الإشراف الإلكتروني يحقق أكثر من نوع من الإشراف كالإشراف بالأقران } \\
\text { والإشراف التعاوني }\end{array}$ \\
\hline 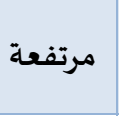 & 12 & $\% 73.2$ & 0.613 & 3.66 & $\begin{array}{c}\text { يساعد الإشراف الإلكتروني باكتشاف المعلمين المتميزين وإبراز تجاربهم } \\
\text { والاستفادة منها. }\end{array}$ \\
\hline مرتفعة & 1 & $\% 85.6$ & 0.565 & 4.28 & 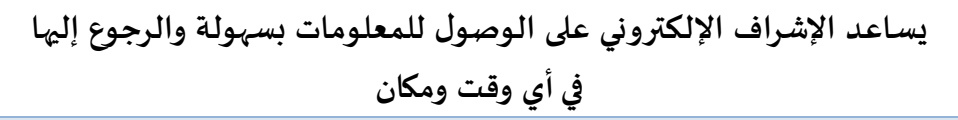 \\
\hline 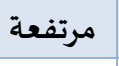 & 5 & $\% 78.8$ & 0.580 & 3.94 & يجب أن يعمل الإشراف الإلكتروني جنباً إلى جنب مع الإشراف التقليدي \\
\hline 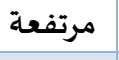 & 9 & \%74.4 & 0.590 & 3.72 & يساعد الإشراف الإلكتروني على تبادل الخبرات بين المشرفين والمعلمين \\
\hline 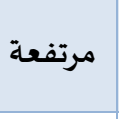 & 10 & \%73.8 & 0.656 & 3.69 & الإشراف الإلكتروني يحقق المتابعة المستمرة للمعلم والتواصل الدائم والتنمية \\
\hline 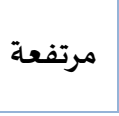 & 4 & $\% 79$ & 0.512 & 3.95 & 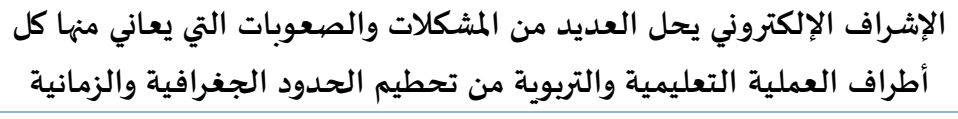 \\
\hline
\end{tabular}




\begin{tabular}{|c|c|c|c|c|c|}
\hline التقدير & الرتبة & النسبية الاوزان & الانحراف & المتوسط الحسابي & الفقرات \\
\hline مرتفعة & 7 & \%76.6 & 0.661 & 3.83 & الإشراف الإلكتروني يوفر درجة من الثقة بالمعلمين وإعطاؤهم الفرصية لممارسـة \\
\hline مرتفعة & 11 & $\% 73.4$ & 0.581 & 3.67 & 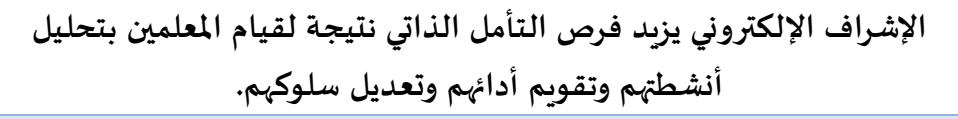 \\
\hline مرتفعة & 2 & \%81.6 & 0.595 & 4.08 & 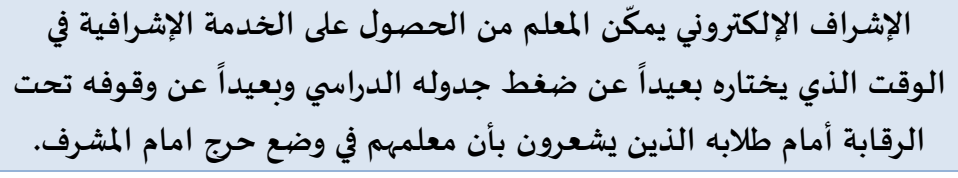 \\
\hline مرتفعة & 3 & \%79.6 & 0.601 & 3.98 & 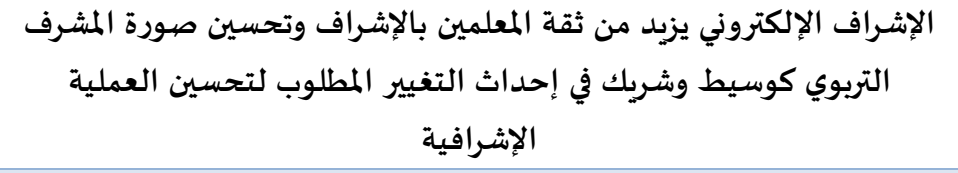 \\
\hline مرتفعة & 6 & $\% 77$ & 0.598 & 3.85 & الدرجـة الكلية \\
\hline
\end{tabular}

\section{أقصى درجة للفقرة 5 درجات}

يتبين من الجدول (9) السابق واقع تطبيق الإشراف الإلكتروني في المدارس الحكومية من وجهاة نظر

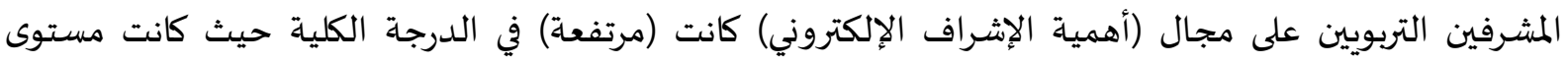

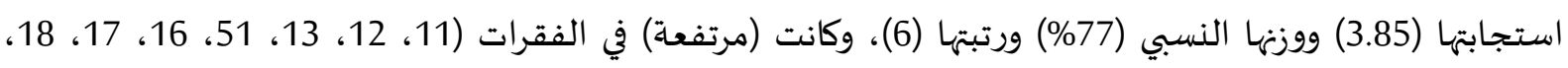

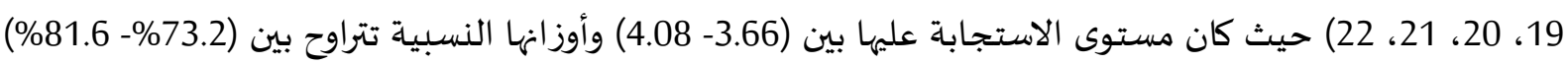

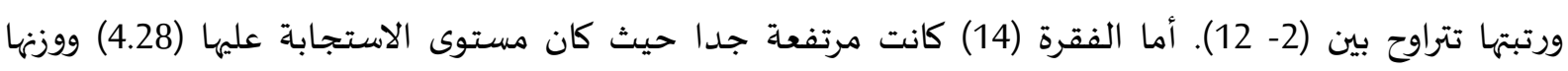
النسبي (85.6) ورتبتها (1).

وهذا مؤشر على أن المشرفين التربويين يعتبرون توظيف الته التكنولوجيا في العمل الإشرافي أمرا ضروريا، لما له

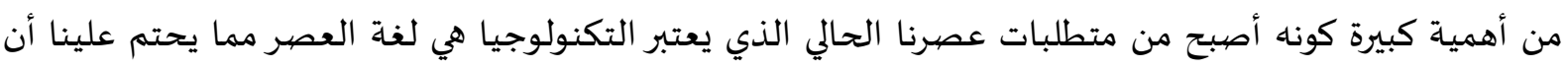

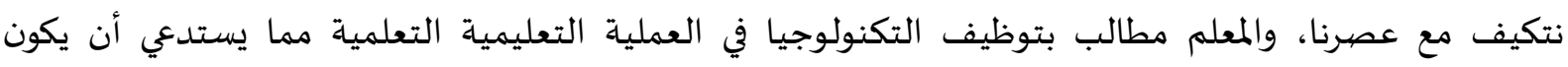

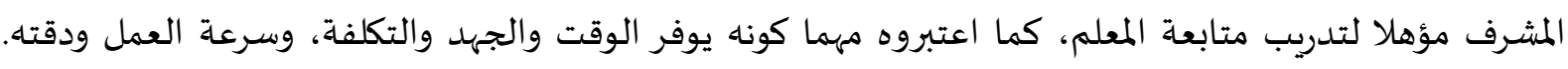

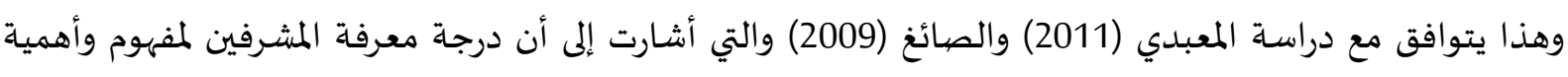
الإشراف الإلكتروني كانت بدرجة كبئ دراسيرة. الجدول (10) المتوسطات الحسابية والنسب المئوية والانحرافات المعيارية والأوزان النسبية والرتبة والتقدير للمجال الثالث (واقع تطبيق الإشراف الإلكتروني)

\begin{tabular}{|c|c|c|c|c|c|}
\hline التقدير & 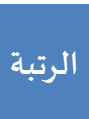 & 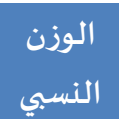 & الانتحراف - المعياري & الحسبط المتوسط & 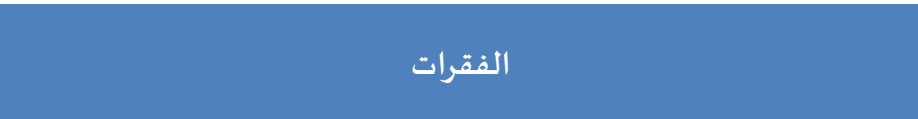 \\
\hline 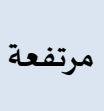 & 6 & \%77.4 & 0.658 & 3.87 & يقوم المشرف التربوي بتقديم برامج وأنشطة تساهم في عملية التطوير الممني \\
\hline 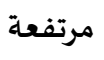 & 8 & $\% 76.8$ & 0.591 & 3.84 & يقوم المشرف التربوي بتشكيل مجموعات تثقيفية وتطويرية. \\
\hline 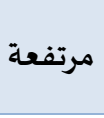 & 1 & $\% 82.0$ & 0.585 & 4.10 & يقوم المشرف التربوي بالعمل على حل المشكلات وإيجاد البدائل المناسبة \\
\hline 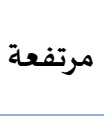 & 2 & $\% .81 .8$ & 0.588 & 4.09 & يقوم المشرف التربوي بالعمل على توجيه المعلمين لاهم المواقع والمنصهات \\
\hline
\end{tabular}




\begin{tabular}{|c|c|c|c|c|c|}
\hline التقدير & الرتبة & 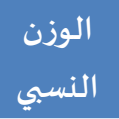 & الانتحراف & المتوسط الحسابي & الفقرات \\
\hline 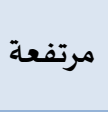 & 8 & $\% 76.8$ & 0.562 & 3.84 & للمشرف التربوي القدرة على تخطي الحواجز المكانية والزمانية لتطبيق \\
\hline 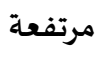 & 7 & $\% 77.0$ & 0.562 & 3.85 & يقوم المشرف التربوي بتقديم الأسـاليب الإشرافية وفق المواقف التعليمية \\
\hline مرتفعة & 10 & \%74.6 & 0.423 & 3.73 & $\begin{array}{c}\text { للمشرف التربوي القدرة على استخدام أدوات التعلم الإلكترونية بكفاءة } \\
\text { وفاعلية. }\end{array}$ \\
\hline مرتفعة & 9 & $\% 75.4$ & 0.512 & 3.77 & يقوم المشرف التربوي بالتكثيف من عملية نشر الوعي بأهمية التعليم \\
\hline 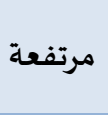 & 3 & $\% 80.2$ & 0.534 & 4.01 & 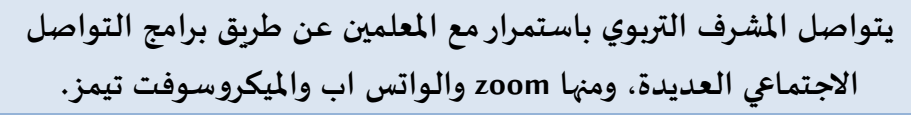 \\
\hline 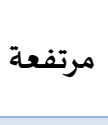 & 4 & \%79.2 & 0.311 & 3.96 & للتأكد من سلامة المشرف التربوي أعمال المعلمين وما يقومون به من خلال هذه البرامج \\
\hline مرتفعة & 5 & \%78.2 & 0.533 & 3.91 & 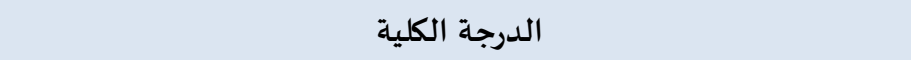 \\
\hline
\end{tabular}

أقصى درجة للفقرة 5 درجات

تبين من الجدول (10) السابق واقع تطبيق الإشراف الإلكتروني في المدارس الحكومية من وجهة نظر الترات

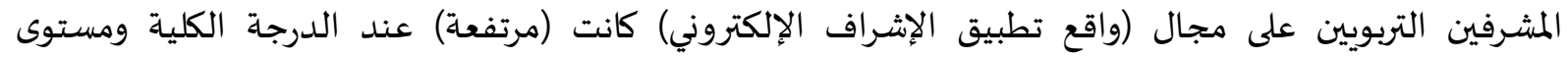
استجابتها كان (78.2\%) ورتبتها (5)، وكانت مرتفعة في جميع الفقرات حيث كان مستوى الاستجابة عليها بين (3.73-

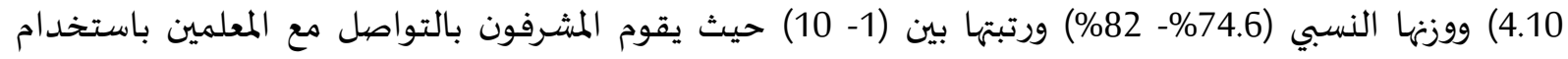
مواقع التواصل المختلفة (زووم، واتس اب، وميكروسوفت تيمر، والفيس بوك والبادلت) وعمل اجتماعات ودورات

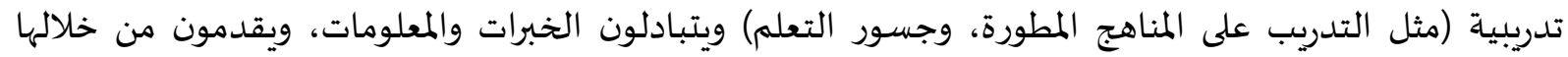
حصص نموذجية مصورة لتصل لشريحة كبيرة من المعلمين والطلبة، ويحدث تفاعل نشط تبدلت من خلاله الأدوار ليصبح المعلم هو من يتوق للخدمة الإشرافية ويطلها ويبحث عنها والمشرف متلق لها، كما سهل هذا الأسلوب التواصل مع المعلمين والمشرفين والطلبة حتى أولياء الامور، وتزويدهم بما هو جديد على على الساحة التعليمية والتربوية

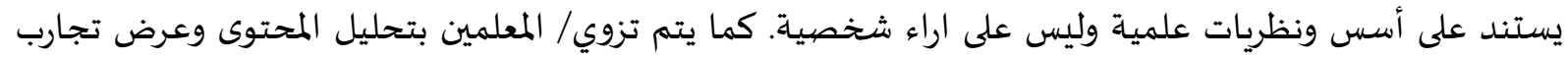
لحوسبة المنهاج والخطط الدراسية وتزويدهم بمواقع تعرض المناهج المحوسبة بشكل مناسب، كما توفر قاعدة

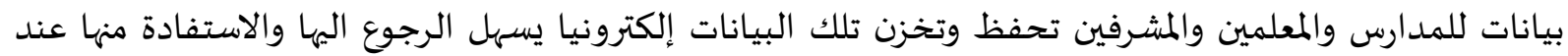
الحاجة. وكذلك النماذج الإشرافية المحوسبة والخلاصة الشهرية حيث يتم تفريغ البيانات عليها وعرض المهرفيات انجازاتهم

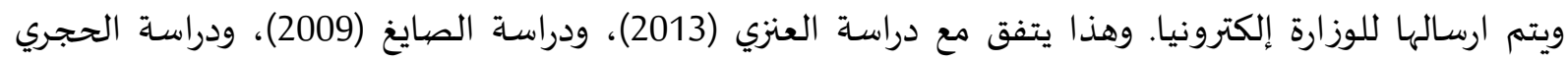

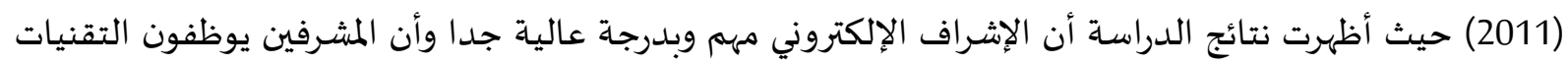

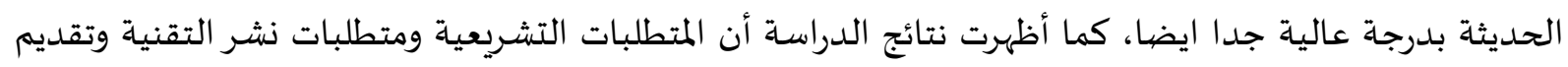

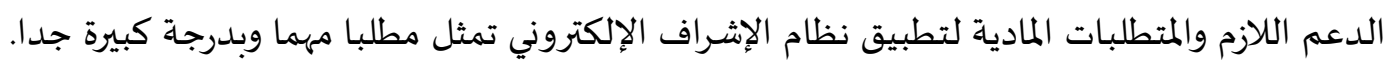

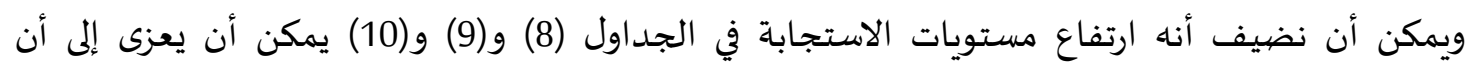

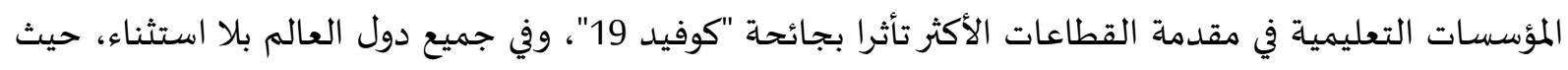

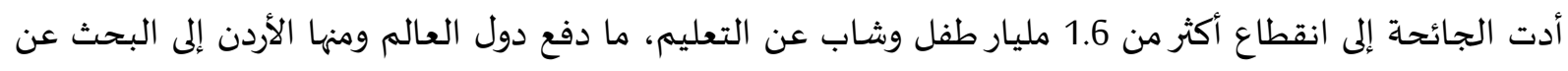

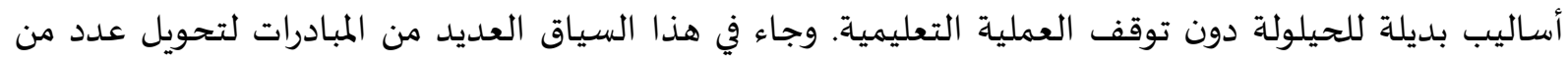


التطبيقات الذكية إلى منصات تعليمية عن بعد. وخلال فترة وجيزة تبدلت ملامح التعليم التقليدي الذي لم يعد

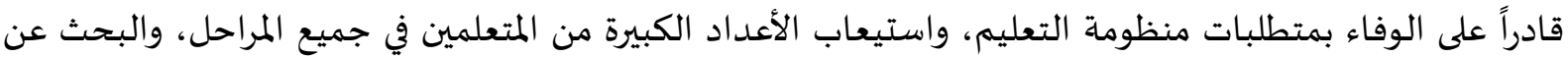

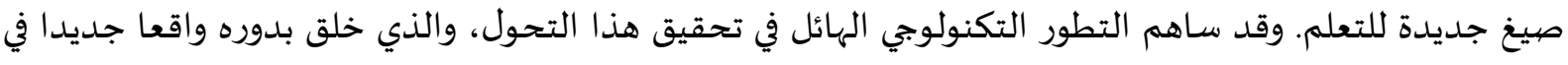

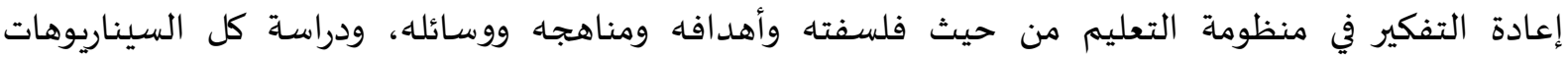
المستقبلية والمتوقعة في مرحلة التعايش مع تلك الجائحة وما بعدها.

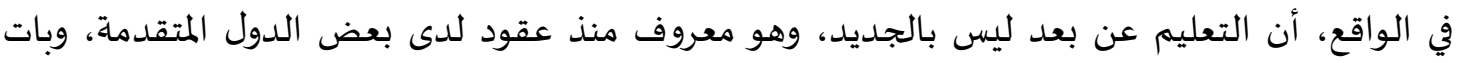

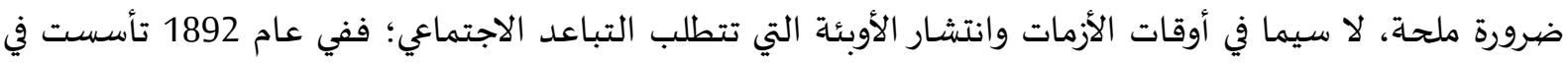

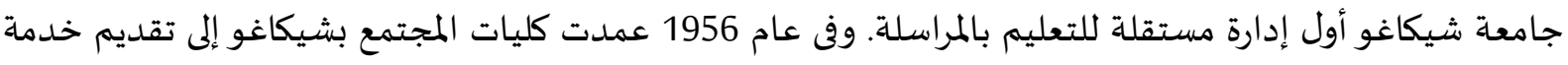

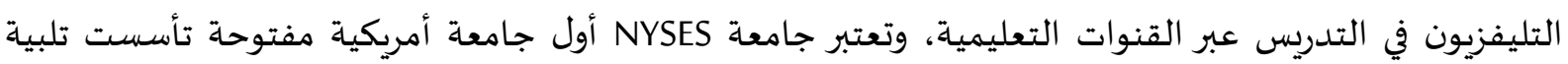

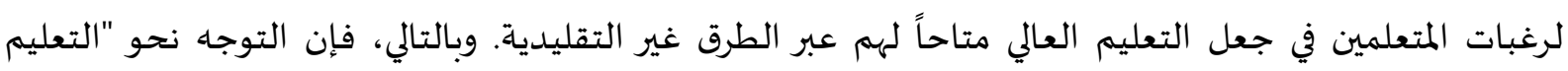

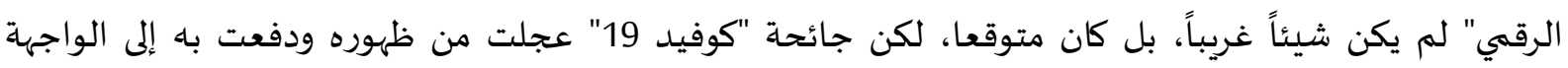

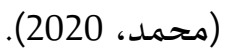
الجدول (11) المتوسطات الحسابية والنسب المئوية والانحرافات المعيارية والاوزان النسبية والرتبة والتقدير للمجال الرابع (معوقات استخدام الإشراف الإلكتروني)

\begin{tabular}{|c|c|c|c|c|c|}
\hline التقدير & الرتبة & 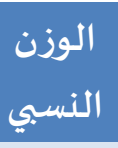 & 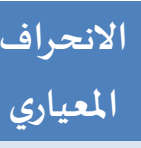 & الحسابي المتوسط & الفقرات \\
\hline 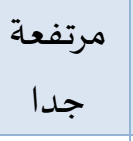 & 1 & $\% 88.4$ & 0.658 & 4.42 & 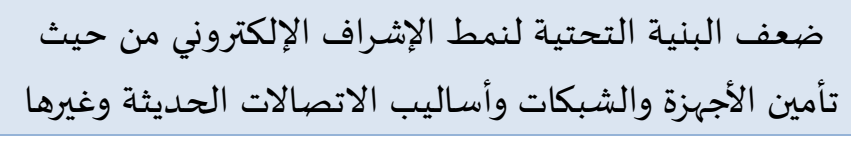 \\
\hline 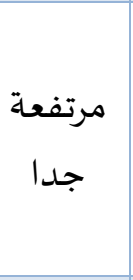 & 2 & $\% 88.0$ & 0.656 & 4.40 & 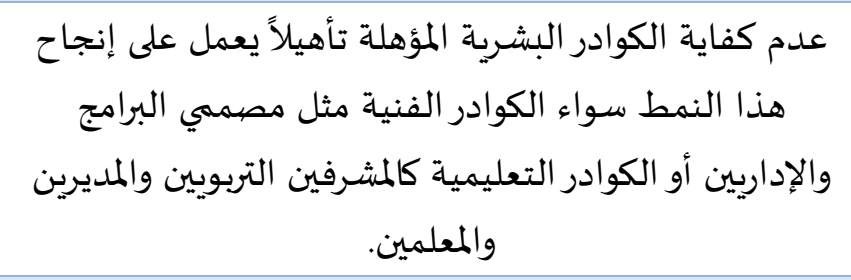 \\
\hline مرتفعة & 3 & $\% 86.8$ & 0.633 & 4.34 & ارتفاع الكلفة المادية لتطبيق هذا النمط سواء من حيث شراء الأجهزة والبرمجيات أو الاتصال بشبكة الإنترنت. \\
\hline مرتفعة & 5 & $\% 80.8$ & 0.655 & 4.04 & صعوبة التخلي السريع عن النظرة التقليدية للإشراف التربوي \\
\hline مرتفعة & 6 & $\% 77$ & 0.690 & 3.85 & المقاومة بعض المشرفين التربويين والمديرين والمعلمين للإشراف \\
\hline \multicolumn{2}{|c|}{ مرتفعة جدا } & $\% 84.2$ & 0.595 & 4.21 & الدرجة الكلية \\
\hline
\end{tabular}

يتبين من الجدول (11) السابق واقع تطبيق الإشراف الإلكتروني في المدارس الحكومية من وجهاة نظر

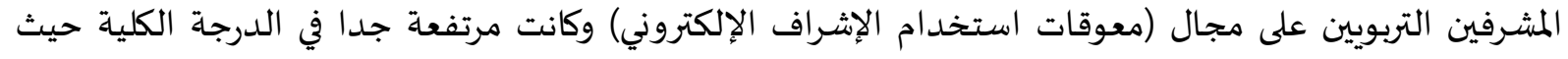

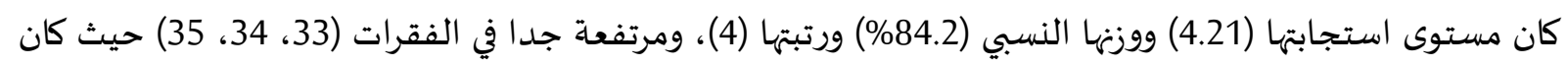

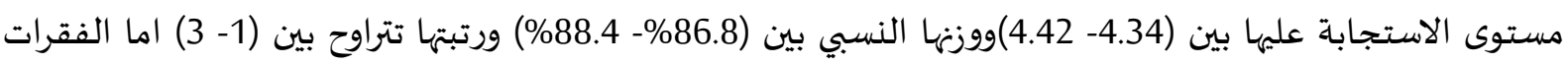


(36، 37) كانت مرتفعة، حيث كان مستوى الاستجابة عليها (4.04 و3.85) واوزانها النسبية (80.8\% و77\% ورتبتها (5)

ويمكن أن تعزى مستويات الاستجابة في الجدول (11) إلى عدم توافر المعلمين القادرين على إتمام عمليّة

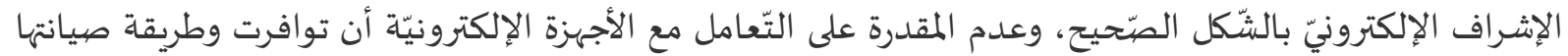
وتشغيلها، ويعود ذلكُّ لعدم توافر دوراتٍ تدربيّيةٍ في هذا المجال.بالإضافة إلى أن جائحة فيروس كورونا أزمة من بين

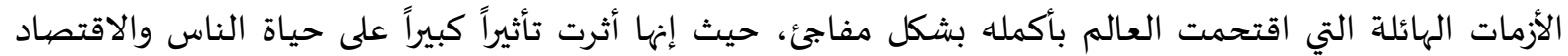
العالي وكافة القطاعات، والتي منها التعليم والذي حاول القائمون عليها تدارك الخسائر والعوائق التي أعاقت استمرار العملية التعليمية وانقطاع الطلاب والطالبات عن التعليم. وقد أظهرت جائحة كورونا ضعف البنية التحتية

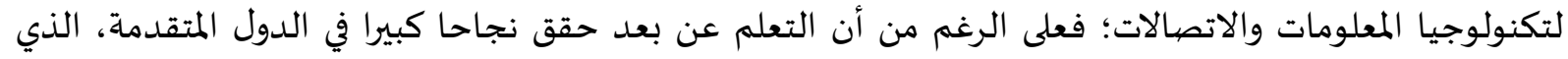
يتمتع ببنية تكنولوجية قوية، لكن الأمر مختلف في حالة الدول النامية، خاصة في ظل هشاشة البنية الرقمية، وارتفاع تكلفة خدمة الإنترنت بالنسبة لمستويات الدخول. لقد أظهرت جائحة "كوفيد 19" حاجتنا إلى نظام تعليمي هائه

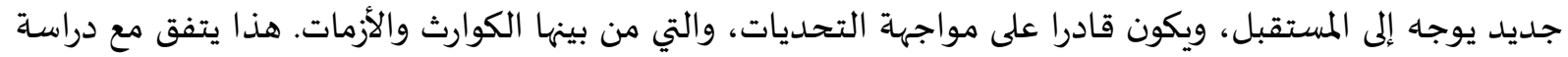

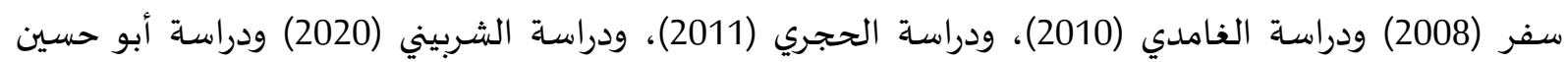

1- النتائج المتعلقة بالإجابة عن السؤال الثاني ونصه: هل يختلف واقع تطبيق الإشراف الإلكتروني في المدارس

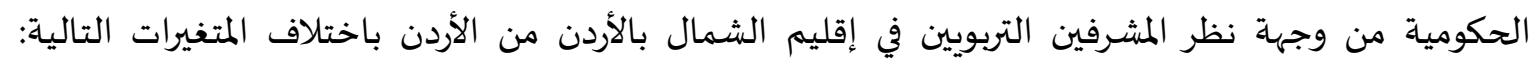

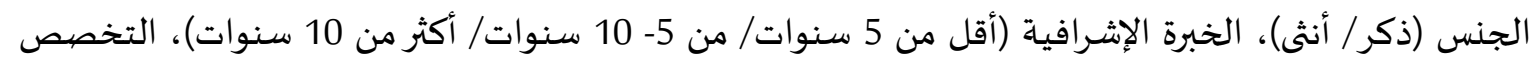
(تخصصات علمياة/ تخصصات أدبية) ؟ لوحظ عدم وجود فروق في النتائج تبعا لمتغير الجنس وسنوات الخبرة الإشرافية والتخصص للمشرفين التربوين. 1- نتائج فحص الفرضية الاولى التي نصها: لا توجد فروق ذات دلالة إحصائية عند مستوى الدلالة (م>0.05)

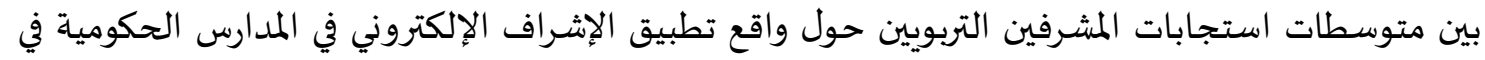
إقليم الشمال بالأردن تبعا لمتغير الجنس. لفحص الفرضية تم استخدام اختبار (ت) والجدول (12) يبين النتائج. الجدول (12) نتائج اختبار (T) لمدى تطبيق الإشراف الإلكتروني في ظل جائحة كورونا من وجهة نظر المشرفين تبعا لمتغير الجنس (ذكر/ ألنثى)

\begin{tabular}{|c|c|c|c|c|c|c|c|}
\hline \multirow{2}{*}{ 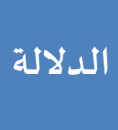 } & \multirow{2}{*}{ (ت) } & \multicolumn{2}{|c|}{ أنثى } & \multicolumn{2}{|c|}{ ذكر } & \multirow{2}{*}{ 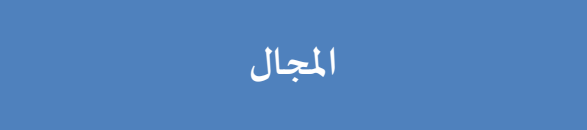 } & \multirow{2}{*}{$\hat{\imath}$} \\
\hline & & الانحراف & المتوسط & الانحراف & المتوسط & & \\
\hline 0.357 & 0.992 & 0.590 & 3.81 & 0.601 & 3.77 & مفهوم الإشراف الإلكتروني & 1 \\
\hline 0.237 & 1.203 & 0.386 & 4.00 & 0.540 & 3.91 & أهمية الإشراف الإلكتروني & 2 \\
\hline 0.480 & 2.125 & 0.547 & 3.91 & 0.502 & 3.90 & واقع تطبيق الإشراف الإلكتروني في الميدان & 3 \\
\hline 0.635 & 0.469 & 0.552 & 4.21 & 0.581 & 4.20 & معوقات استخدام الإشـراف الإلكتروني & 4 \\
\hline 0.652 & 0.496 & 0.518 & 4.00 & 0.556 & 3.95 & المجموع & \\
\hline
\end{tabular}

دال احصائيا عند مستوى الدلالة (0.05) 


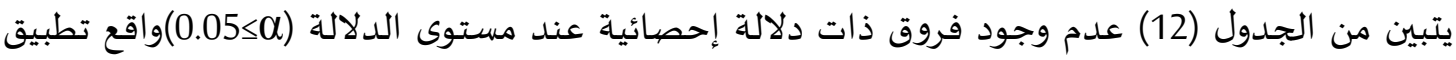

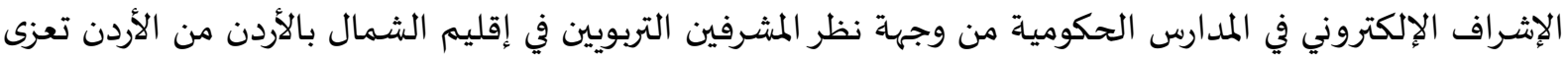

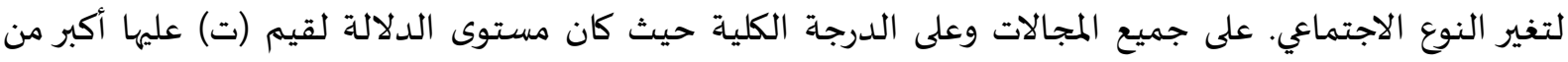
(0.05) وبهذا تقبل الفرضية الصفرية. وتعزو الباحثة إلى أن المشرفين سواء كانوا ذكورا أو اناثا يهتمون بتطبيق الإثراف الإلكتروني في الميدان

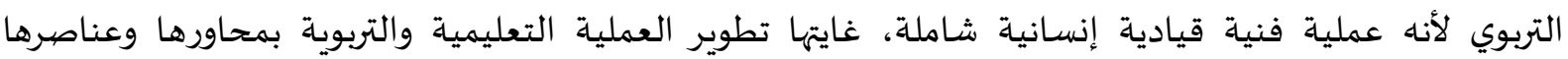

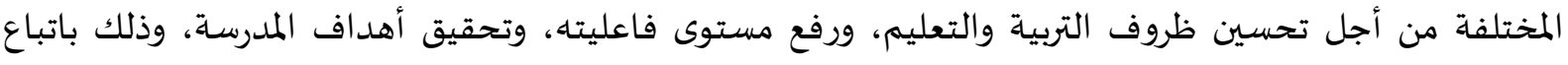

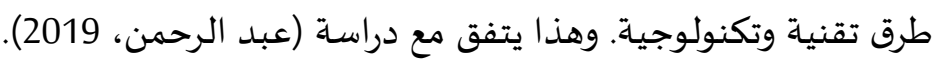

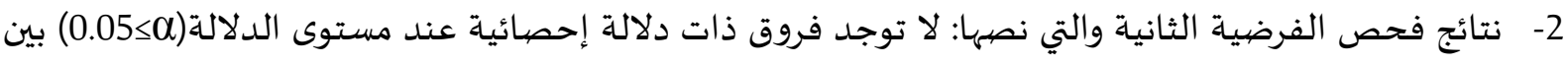

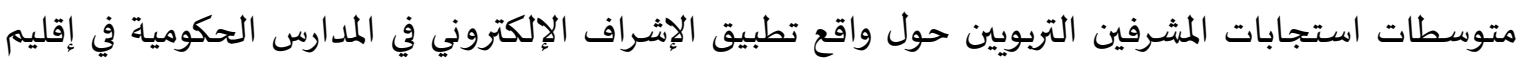
الشمال بالأردن تبعا لمتغير الخبرة الإشرافية. لفحص الفرضية تم استخدام اختبار (ت) والجدول (13) يبين النتائج. الجدول (13) نتائج اختبار (T) لمدى تطبيق الإشراف الإلكتروني في ظل جائحة كورونا من وجهة نظر المشرفين تبعا لمتغير الخبرة الإشرافية

\begin{tabular}{|c|c|c|c|c|c|c|c|c|}
\hline الدلالة & (ت) & 1 سنوات 1 سانحراف & أكتر من & الانحراف سنوات & من 5- 0 & الانحراف سنوات & أقلم من ألموسط & المجال \\
\hline 0.118. & 0.972 & 0.581 & 3.62 & 0.587 & 3.75 & 0.613 & 3.89 & مفهوم الإشـراف \\
\hline 0.255 & 1.978 & 0.584 & 3.32 & 0.510 & 3.82 & 0.624 & 4.02 & أهمية الإشراف \\
\hline 0.291 & 1.978 & 0.589 & 3.58 & 0.629 & 3.78 & 0.402 & 3.82 & والإلع تطبيق الإشراف \\
\hline 0.570 & 1.865 & 0.510 & 3.23 & 0.755 & 3.87 & 0.322 & 4.28 & الإشـراف الإلكتروني \\
\hline 0.721 & 0.624 & 0.568 & 3.44 & 0.628 & 3.812 & 0.501 & 4.00 & المجموع \\
\hline
\end{tabular}

دال احصائيا عند مستوى الدلالة (0.05) يتبين من الجدول (13) (12) عدم وجود فروق ذات دلالة إحصائية عند مستوى الدلالة (م_0.05) واقع

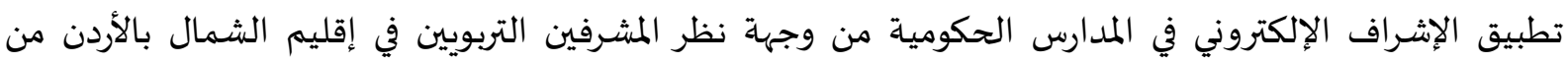

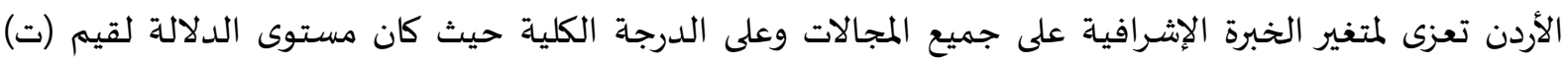

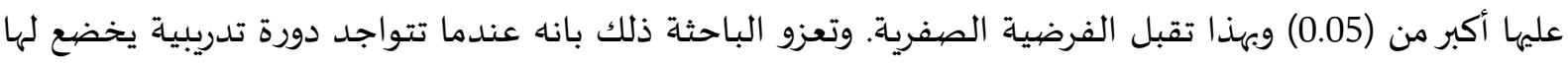

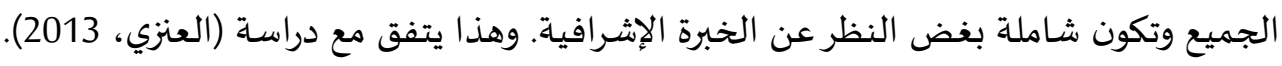

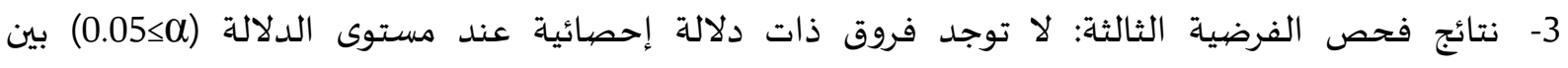

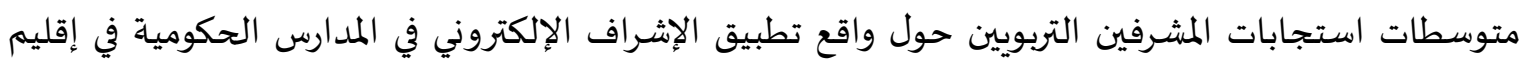
الشمال بالأردن تبعا لمتغير التخصص. لفحص الفرضية تم استخدام اختبار (ت) والجدول (14) يبين النتائج. 
الجدول (14) نتائج اختبار (T) لمدى تطبيق الإشراف الإلكتروني في ظل جائحة كورونا من وجهة نظر المشرفين

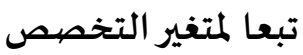

\begin{tabular}{|c|c|c|c|c|c|c|c|}
\hline \multirow{2}{*}{ 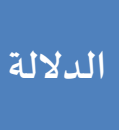 } & \multirow{2}{*}{ (ت) } & \multicolumn{2}{|c|}{ التخصيصات الادبية } & \multicolumn{2}{|c|}{ التخصصيات العلمية } & \multirow{2}{*}{ المجال } & \multirow{2}{*}{$\hat{\imath}$} \\
\hline & & الانحراف & المتوسط & الانحراف & المتوسط & & \\
\hline 0.268 & 1.852 & 0.595 & 3.72 & 0.631 & 3.89 & مفهوم الإشراف الإلكتروني & 1 \\
\hline 0.521 & 1.947 & 0.586 & 3.45 & 0.640 & 3.97 & أهمية الإشراف الإلكتروني & 2 \\
\hline 0.424 & 2.022 & 0.664 & 3.32 & 0.594 & 3.95 & واقع تطبيق الإشراف الإلكتروني في & 3 \\
\hline 0.635 & 0.675 & 0.642 & 4.20 & 0.601 & 4.28 & معوقات استخدام الإشراف & 4 \\
\hline 0.652 & 0.496 & 0.518 & 4.00 & 0.556 & 3.95 & المجموع & \\
\hline
\end{tabular}

يبين من الجدول (14) عدم وجود فروق ذات دلالة إحصائية عند مستوى الدلالة (0.05 0.05) واقع تطبيق

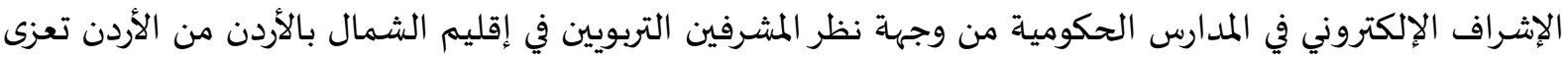
لمتغير التخصص على جميع المجالات وعلى الدرجة الكلية حيث كان مستوى الدلالة لقيم (ت) عليها أكبر من (0.05)

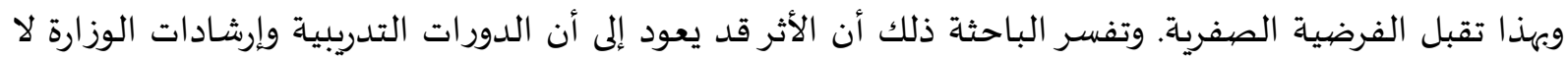

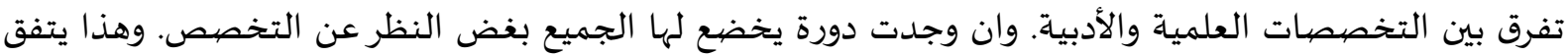
مع دراسـة (عبد الرحمن، 2019).

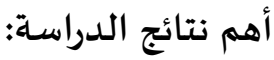
1- أظهرت جائحة "كوفيد 19" حاجتنا إلى نظام تعليمي جديد يوجاه إلى المستقبل، ويكون قادرا على مواجهة التحديات، والتي من بينها الكوارث والأزمات. 2- المشرفين التربويين يعتبرون توظيف التكنولوجيا في العمل الإشرافي أمرا ضروريا، لما له من أهمية كبيرة كونه

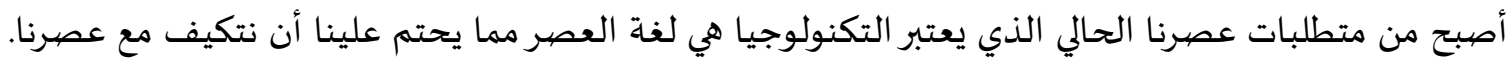
3- الإشراف الإلكتروني ساعد المعلمين على التفاعل النشط مع المشرف التربوي بصورة متزامنة أو غير متزامنة.

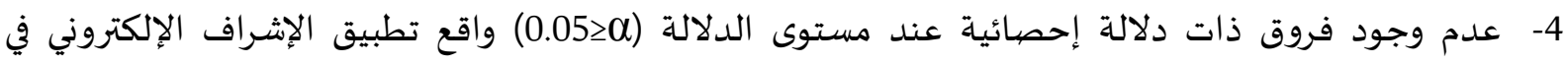

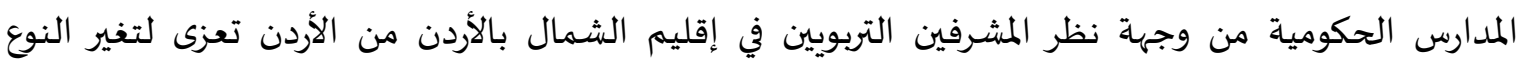
الاجتماعي. 5- عدم وجود فروق ذات دلالة إحصائية عند مستوى الدلالة (0.05>0) واقع تطبيق الإشراف الإلكتروني في

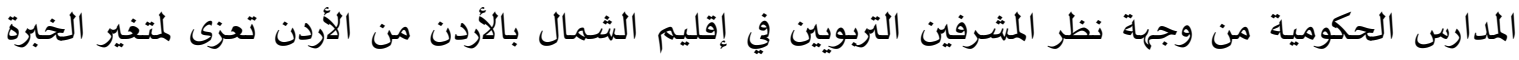
الإشرافية 6- عدم وجود فروق ذات دلالة إحصائية عند مستوى الدلالة (0.05>0) واقع تطبيق الإشراف الإلكتروني في

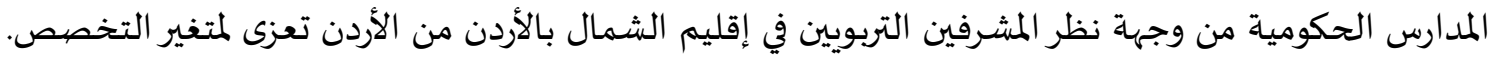


في ضوء ما توصلت إليه الدراسة من نتائج توصي الباحثة وتقترح بما يلي:

1.

2. الحفاظ على سير العملية التعليمية في ظل ظروف جائحة كورونا؛ مع الأخذ بعين الاعتبار أهمية الصحة المانة

بالنسبة للمعلم والطالب ولكافة أفراد المجتمع.

3. أن يطور المشرف التربوي ممارساته الإشرافية لتتفق مع ظروف جائحة كورونا، ولتتفق مع متطلبات التعليم

الإلكتروني.

4. دعم المعلم بوسائط تعليمية يمكنه الاستناد إليها عند تصهميم دروسه الإلكترونية.

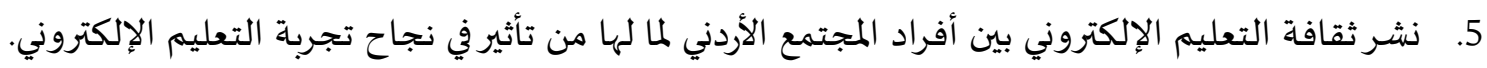

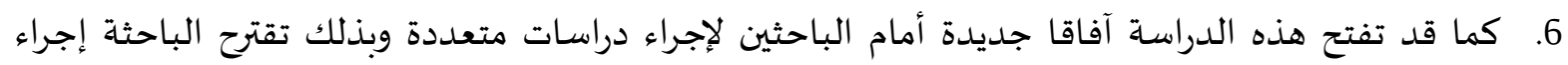
دراسـة تتناول: سبل تطوير منظومة الإشراف الإلكتروني في وزارة التربية والتعليم الأردنية.

قائمة المراجع

أولاً - المراجع بالعربية:

- أبو حسين، فاطمة (2021). معوقات ممارسة الإشراف الإلكتروني من وجهة نظر المشرفات في مدينة أبها

الحضرية. رسالة ماجستير غير منشورة. كلية التربية- جامعة الملك خالد- المملكة العربية السعودية.

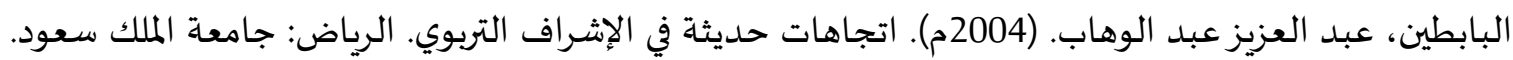

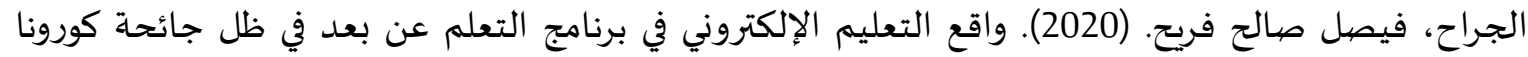
المستجد "كوفيد 19" من وجهة نظر الطلبة في الأردن بين النظرية والتطبيق .مجلة العلوم التربوية والنفسية:

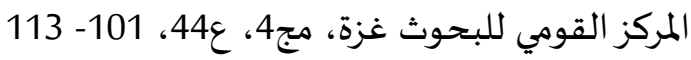

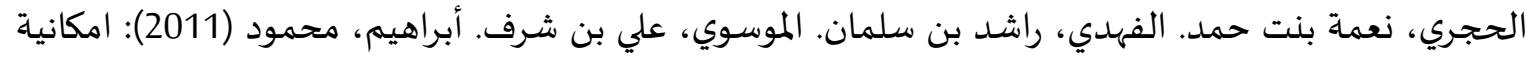

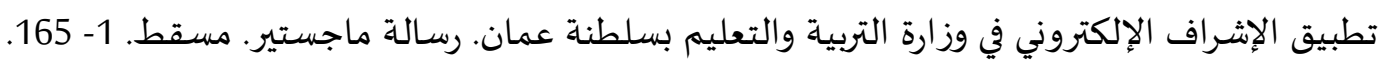
خلف الله، محمود إبراهيم. (2014). تصور مقترح لتطبيق الإشراف التربوي الإلكتروني على الطلبة والمعلمين

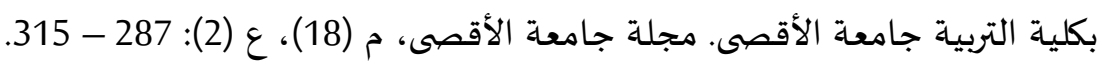

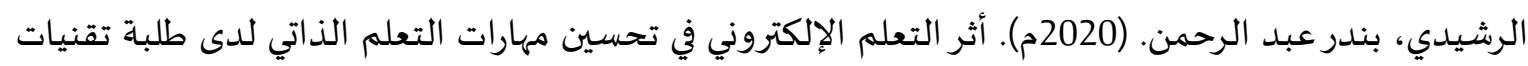

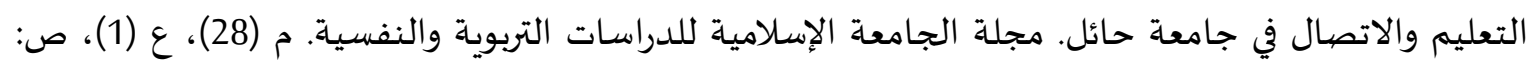
$.161-141$ السرحان، خالد. (2011). نمط الإشراف التربوي في مديريات التربية والتعليم في محافظة المفرق من وجهة نظر

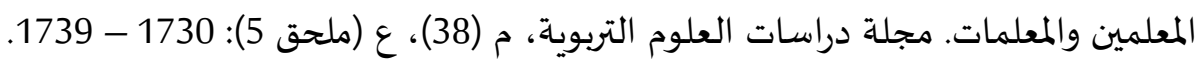

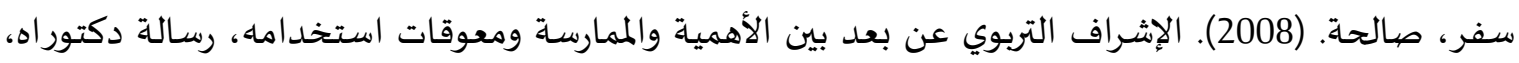

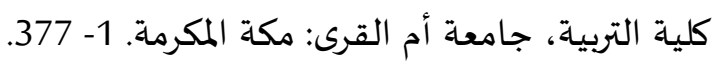

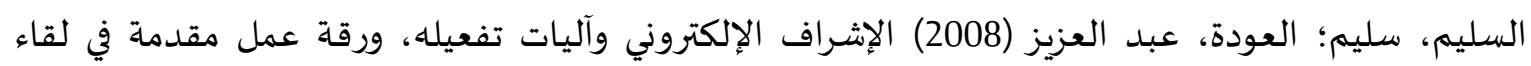
الإشراف التربوي الثالث عشر لمديري إدارات ومراكز الإشراف التربوي المقام في منطقة حائل 
السوالمة، سالم معيوف؛ القطيش، حسين مشوح (2015) استخدام المشرفين التربويين للإنترنت في الإشراف

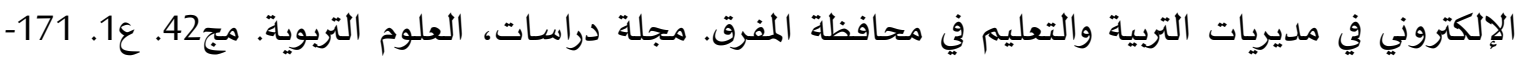

الشربيني، محمد محمد (2020): متطلبات استخدام الإشراف الإلكتروني في التدريب الميداني في الخدمة الاجتماعية. مجلة دراسات في الخدمة الاجتماعية والعلوم الانسانية. جامعة حلوان- كلية الخدمة الاجتماعية.

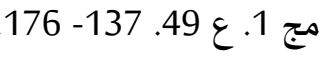

الشمراني، محمد (2008) الإشراف الإلكتروني (مفهومه - أهدافه - إجراءاته التطبيقية)ورقة عمل مقدمة في لقاء مديري إدارات الإشراف التربوي الأحساء.

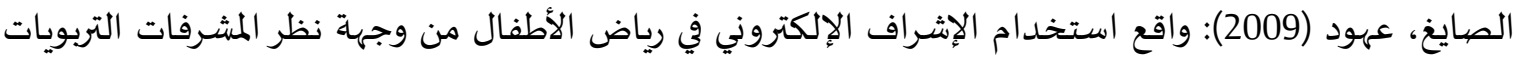

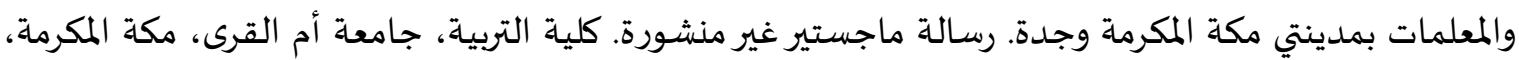
المملكة العربية السعودية.

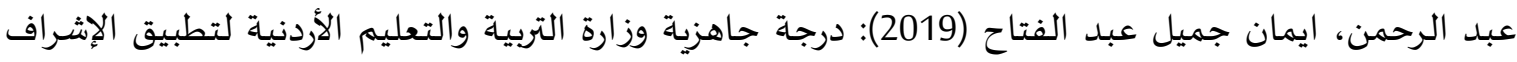

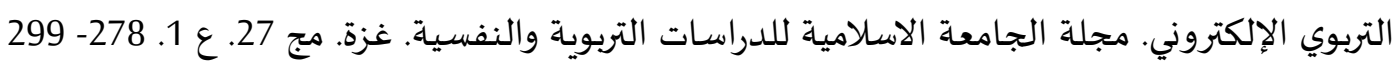

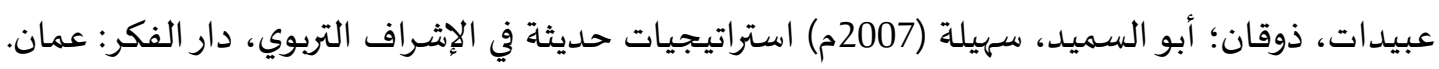

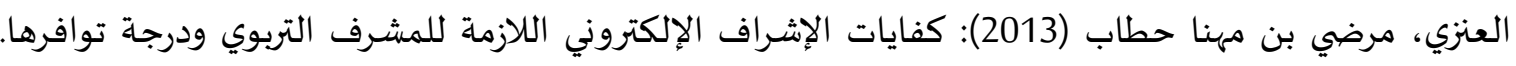

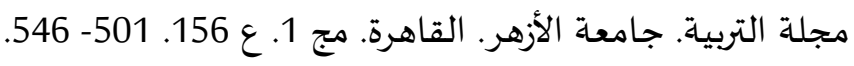
الغامدي، محمد بن عبد الله محمد؛ لال، زكريا بن يحيح (2010) أهمية ومعوقات الإشراف التربوي التربي الإلكتروني

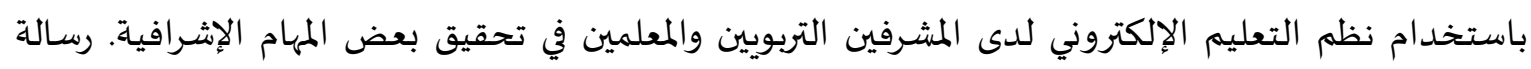
ماجستير. جامعة أم القرى. مكة المكرمة. السعودية. 1- 185 القره غولي، صفا عبد الرضا عبد الجليل. (2019). واقع استخدام التعليم الإلكتروني لتطوير التعليم والتعلم في ماتي المدارس الثانوية من وجهة نظر المدرسين والمدرسات .مجلة الفنون والأدب وعلوم الإنسانيات والاجتماع: كلية

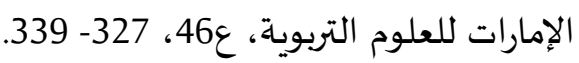
كنسارة، إحسان وعطار، عبد الله. (2013م). الجودة الشاملة في التعلم الإلكتروني. مكة المكرمة: مؤسسة بهادر لإعلام والتطور. المالك، منيرة بنت عبد الله؛ الدرويش، عبد العزيز بن سلمان (2020): واقع تطبيق الإشراف الإلكتروني لدى

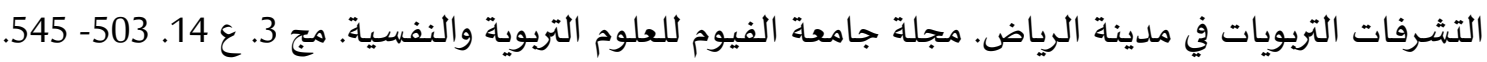
محمد، بشرى ياسين. (2020م). معالجة مشكلات تعلم الطلبة من خلال استخدام التعليم الإلكتروني. المجلة

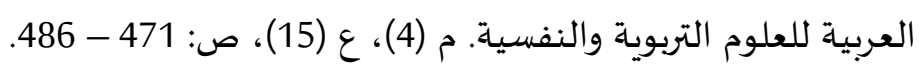
المعبدي، حنس (2011): الإشراف الإلكتروني في التعليم العام (الواقع والمأمول) رسالة ماجستير غير منشورة. كلية التربية، جامعة أم القرى، المملكة العربية السعودية. المغذوي، حامد عايض ربيع؛ فرج، عبد اللطيف بن حسين بن ابراهيم (2008): فاعلية الإشراف الإلكتروني في

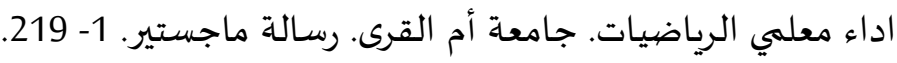

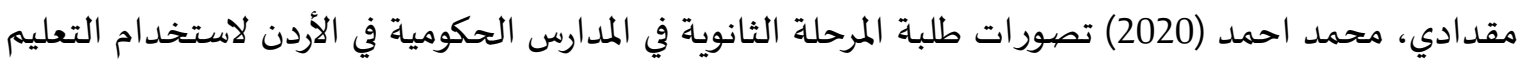
عن بعد في ظل ازمة كورونا ومستجداتها. مج ()ع (19) المجلة العربية للنشر العلمي. 96- 114. 


\section{ثانياً- المراجع بالإنجليزية:}

- Aljaser, A. M. (2019). The effectiveness of e- learning environment in developing academic achievement and the attitude to learn English among primary students. Turkish Online Journal of Distance Education- TOJDE, 20 (2), 194 -176

- Carboni, L and Riggsbee, J. (2007) We needed support and it was out there: Building an online Learning Community with Cooperating Teachers. Electronic Journal for the Integration of Technology in Education, 6, 109- 121.

- Draissi, Z., \& ZhanYong, Q. (2020). COVID- 19 Outbreak Response Plan: Implementing Distance Education in Moroccan Universities. Available at SSRN 3586783.

- Favale, T., Soro, F., Trevisan, M., Drago, I., \& Mellia, M. (2020). Campus traffic and e- Learning during COVID- 19 pandemic. Computer Networks, 176, 107290.

- Hodges, C., Moore, S., Lockee, B., Trust, T., \& Bond, A. (2020). The difference between emergency remote teaching and online learning. Educause review, 27, 1- 12

- MOE (2019) Official website of the Jordanian Ministry of Education

- Van Horn, Stacy M.; Robert D. (2001). Computer technology and the 21st Century school counselor: American School Counselor Association,2009. 